\title{
Examining the effectiveness of older and younger adults' strategies for solving interpersonal and individual everyday problems
}

Joseph P. McFall

West Virginia University

Follow this and additional works at: https://researchrepository.wvu.edu/etd

\section{Recommended Citation}

McFall, Joseph P., "Examining the effectiveness of older and younger adults' strategies for solving interpersonal and individual everyday problems" (2007). Graduate Theses, Dissertations, and Problem Reports. 4319.

https://researchrepository.wvu.edu/etd/4319

This Thesis is protected by copyright and/or related rights. It has been brought to you by the The Research Repository @ WVU with permission from the rights-holder(s). You are free to use this Thesis in any way that is permitted by the copyright and related rights legislation that applies to your use. For other uses you must obtain permission from the rights-holder(s) directly, unless additional rights are indicated by a Creative Commons license in the record and/ or on the work itself. This Thesis has been accepted for inclusion in WVU Graduate Theses, Dissertations, and Problem Reports collection by an authorized administrator of The Research Repository @ WVU. For more information, please contact researchrepository@mail.wvu.edu. 
Examining the Effectiveness of Older and Younger Adults' Strategies for Solving Interpersonal and Individual Everyday Problems

Joseph P. McFall

Thesis submitted to the Eberly College of Arts and Sciences at West Virginia University in partial fulfillment of the requirements

for the degree of

\author{
Master of Science \\ in \\ Psychology
}
JoNell Strough, Ph.D., Chair
Julie Hicks Patrick, Ph.D.
Philip N. Chase, Ph.D.

Department of Psychology

Morgantown, West Virginia

2007

Keywords: adulthood, everyday problem solving, strategy effectiveness, successful aging Copyright 2007 Joseph P. McFall 


\begin{abstract}
Examining the Effectiveness of Older and Younger Adults'

Strategies for Solving Interpersonal and Individual Everyday Problems
\end{abstract}

Joseph P. McFall

Individual difference characteristics (i.e., age, gender, self-efficacy beliefs, exposure to problems) and contextual characteristics (i.e., problem domain) of the everyday problem-solving process were considered in an examination of individuals' strategy effectiveness. Although prior research has examined problem-solving strategy effectiveness according to independent judges or experts (Allaire \& Marsiske, 2002; Blanchard-Fields, Mienaltowski, \& Baldi, 2007; Cornelius \& Caspi, 1987; Galambos, MacDonald, Naphtali, Cohen, \& de Frias, 2005; Marsiske \& Willis, 1995), methodological weaknesses in determining the effectiveness of the strategies may have invalidated the findings. A group of seven highly reliable expert raters were recruited to provide effectiveness ratings of strategies generated and chosen as most effective by younger $(N=74)$ and older $(\mathrm{N}=74)$ adults in Strough's (2004) study on collaboration and everyday problem solving. Repeated-measures ANOVA on adults' strategy effectiveness scores revealed significant two-way interactions between gender and problem domain and age and problem domain. Men and women had higher effectiveness scores on the finance problem than on the gossip problem, but the difference was more pronounced for men than for women. Younger adult men performed worse than older adult men, younger adult women, and older adult women on the gossip problem. These findings were consistent with previous literature on age and domain difference in problem-solving effectiveness, specifically that older adults outperform younger adults and individuals are more effective for solving instrumental domain problems than interpersonal domain problems (Blanchard-Fields et al., 2007). Mediation models were assessed via path analysis to explain the age effect found in the present study. Exposure to gossip problems was a significant mediator of the age differences in strategy effectiveness. Greater exposure to gossip problems was associated with lower strategy effectiveness scores. Younger adults, who reported greater exposure, used strategies that were less likely to solve the problem or prevent/minimize future occurrences of the problem, which reduced the strategy effectiveness scores. Previous research has shown that younger adults report greater general familiarity with everyday problems than do older adults (Blanchard-Fields, Chen, \& Norris, 1997). The present study suggested that younger adults may report this greater experience because they also reported more present exposure to problematic situations and used less effective strategies. Limitations of the present study include the cross-sectional nature of the design, the limited number of problems examined, and limits on ecological validity when using hypothetical problem vignettes to measure everyday problem solving. 


\section{TABLE OF CONTENTS}

TITLE PAGE . ABSTRACT .

TABLE OF CONTENTS

ACKNOWLEDGEMENTS

LIST OF TABLES

LIST OF FIGURES .

LIST OF APPENDICES

INTRODUCTION

Models of Everyday Problem Solving

Examining Problem-Solving Effectiveness

Independent Judges

Expert Opinion

Problem Domain

Age-Cohort Differences

Gender

Exposure to Problems .

Self-Efficacy Beliefs .

Statement of the Problem

Research Questions and Hypotheses .

Research Question 1 .

Research Question 2 .

METHOD

Design .

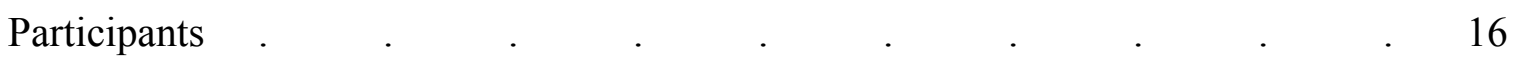

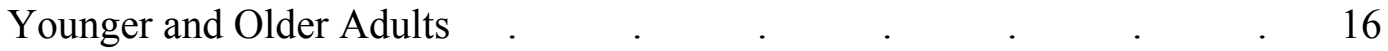

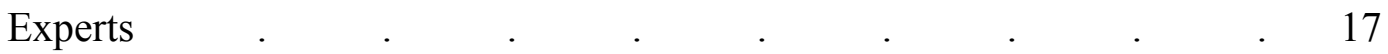

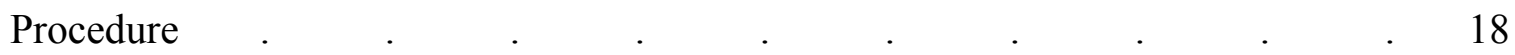

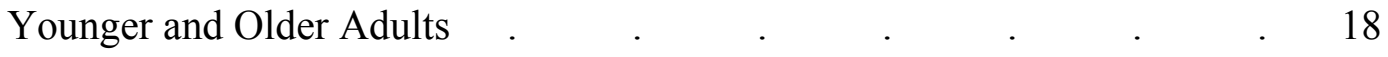

Experts 


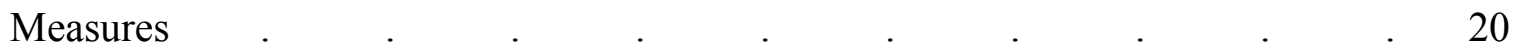

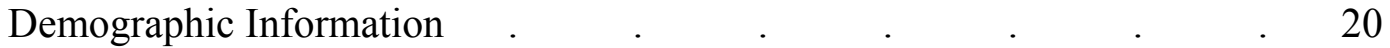

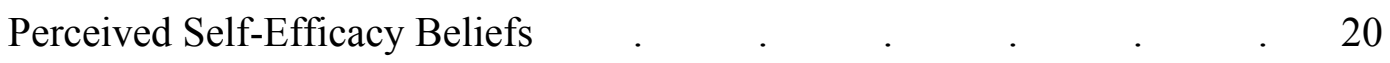

Everyday Problem-Solving Vignettes. $\quad . \quad$. $\quad . \quad$. $\quad$. 21

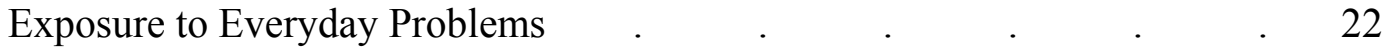

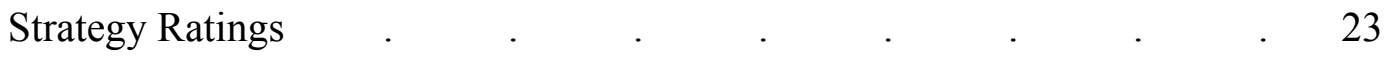

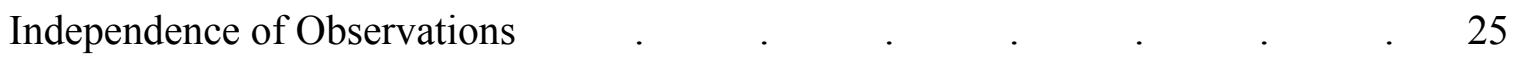

ANALYSES .

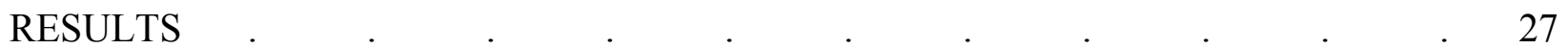

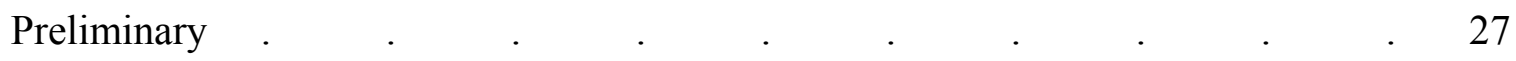

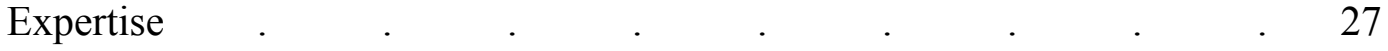

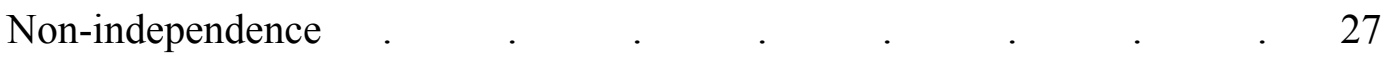

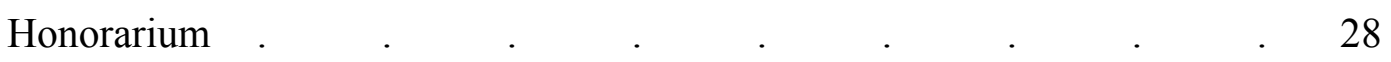

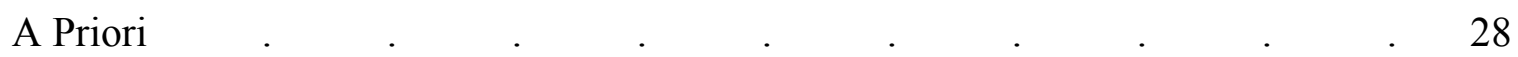

Overall Strategy Effectiveness Ratings _ . $\quad$. $\quad$. $\quad$. $\quad$. 29

Mediation of Age Difference in Strategy Effectiveness $\quad . \quad$. $\quad 30$

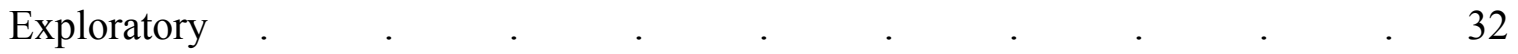

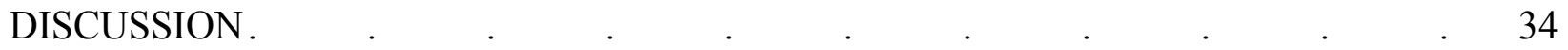

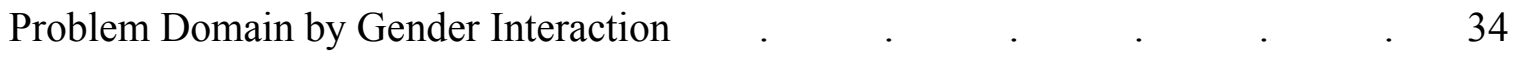

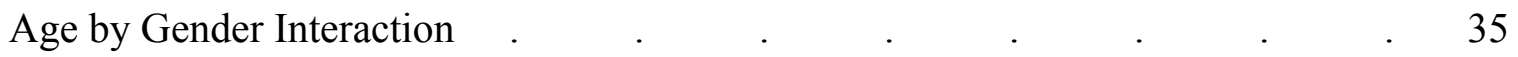

Exposure as a Mediator of Interpersonal Problem Solving 35

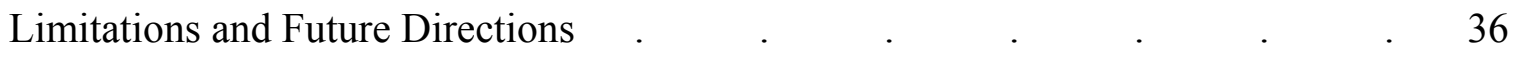

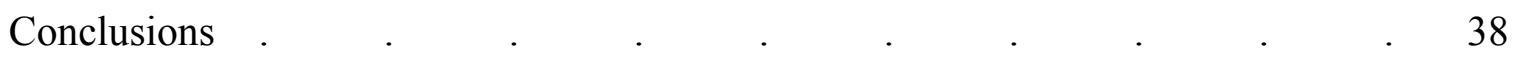

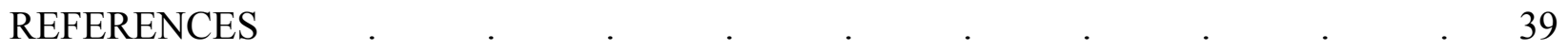

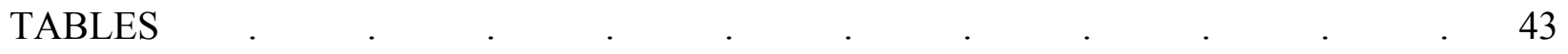

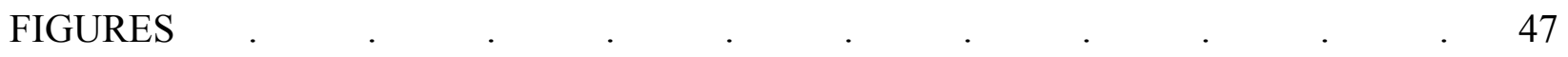

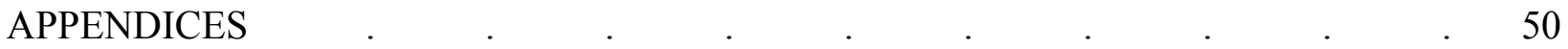




\section{ACKNOWLEDGEMENTS}

I would like to acknowledge the members of my thesis committee: Dr. JoNell Strough (Chair), Dr. Julie Hicks Patrick, and Dr. Philip N. Chase. Their thoughtful contributions to this project have greatly improved the project and stimulated ideas for future directions. I would like to especially thank my advisor, Dr. JoNell Strough, for her countless hours of work, not only in support of this project, but also for her vital role in my continuing intellectual and professional development. I must also acknowledge the financial support of this project via the WVU Department of Psychology Alumni Fund. This fund has aided many graduate students over the years in reducing the financial burden of conducting thesis and dissertation research. Finally, but certainly not least, many thanks go out to my close friends and family for their important contributions to my social support. 


\section{LIST OF TABLES}

1. Older and Younger Adults' Strategies for Solving the Gossip Problem:

Average Expert Ratings and Percentage Selecting by Age Group . . . . . 43

2. Older and Younger Adults' Strategies for Solving the Finance Problem:

Average Expert Ratings and Percentage Selecting by Age Group 44

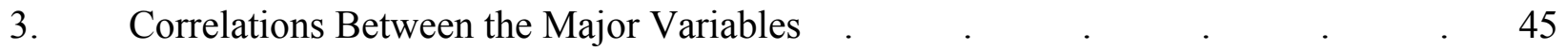

4. Mediation of the Age Difference in Overall Strategy Effectiveness for Solving the Gossip Problem through Exposure with the Gossip Problem:

Standardized and Unstandardized Coefficients and Standard Error (S.E.) 46 


\section{LIST OF FIGURES}

1. Overall Strategy Effectiveness Scores: Problem Domain X Gender . 47

2. Overall Strategy Effectiveness Scores: Age X Gender _ . . . . . 48

3. Path Model 1: Exposure to the Gossip Problem as a Mediator of Age Differences in Strategy Effectiveness Scores for the Gossip Problem . 49 


\section{LIST OF APPENDICES}

APPENDIX A: Demographics Questionnaire $\quad . \quad$. $\quad . \quad$. $\quad$. $\quad$. 50

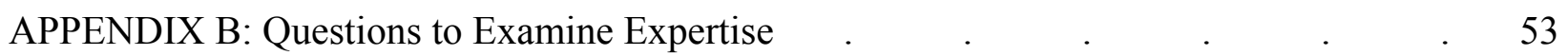

APPENDIX C: Self-Efficacy Scale: Perceived Ability Compared

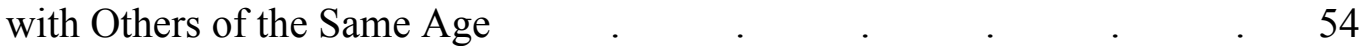

APPENDIX D: Self-Efficacy Scale: Change in Perceived Ability

Over the Past Several Years . $\quad . \quad$. $\quad . \quad$. $\quad . \quad 56$

APPENDIX E: Strough et al. (2007) Strategy Coding Scheme _ . . . . . 57

APPENDIX F: Problem Vignettes and Representative Strategies

to be Rated by Experts _ . . . . . . . . . 59 


\section{Introduction}

Understanding younger and older adults' problem-solving strategy effectiveness is important both in creating a basic scientific understanding of problem solving and a vital prerequisite to improving people's problem-solving in everyday life. What use is a problem solving strategy to science or the application of science if that strategy does not actually work to solve a problem or is ineffective in a problematic encounter? Existing everyday problem-solving literature has not adequately addressed strategy effectiveness; much work is needed in the area to provide both science and the people it serves with an understanding of what makes a strategy effective in some situations, but not useful in others.

The goal of the present research was to examine factors associated with effectiveness of strategies used to solve different types of everyday problems. Only a few everyday problemsolving studies have addressed the issue of effectiveness. These studies have examined age and problem domain differences in strategy effectiveness, but have had problems in terms of the methods for measuring effectiveness. For example, effectiveness ratings have either been based on potentially biased judges or have repeatedly used judges' ratings that were acquired two decades prior. Therefore, the issue of strategy effectiveness remains unclear for current cohorts. Moderating mechanisms (age, domain, gender) and mediating mechanisms (self-efficacy beliefs, exposure to problems) are examined in order to uncover systematic differences in strategy effectiveness.

\section{Models of Everyday Problem Solving}

Everyday problem solving, as defined by Thornton and Dumke's (2005) meta-analysis on everyday problem-solving and decision-making effectiveness, consists of two to three components: the identification of a problematic situation that may commonly occur in people's lives, generation of more than one strategy to solve the problem, and/or the decision of which strategy to enact given particular desired results or goals. D'Zurilla, Nezu, and Maydeu-Olivares (2004) add that a self-directed cognitive-behavioral process accounts for the generation of various potential effective strategies to solve a specific problematic situation, which increases the chances of selecting the most-effective strategy. They describe a problem as a situation (originating due to task demands or within-person demands) that requires an individual to produce some behavioral response (strategy) in order to achieve adaptive functioning because an effective strategy is not automatically available. Finally, an effective strategy is a response 
pattern that solves the problem, maximizes other beneficial consequences of responding, and minimizes potential negative outcomes (D'Zurilla et al., 2004).

Problem-solving researchers have developed theoretical models to examine the interplay of mechanisms that influence individuals' responses to social and task-based situations (Crick \& Dodge, 1994; D’Zurilla et al., 2004; Sansone \& Berg, 1993). The models share several features, including the identification of contextual and individual characteristics that influence peoples' interpretations/definitions (i.e., experientially-subjective representations of a problem's contextual aspects) of situations, generation of potential strategies, and choice of the best strategy for enactment. It should be noted, however, that individuals' behavior in any problematic situation is in response to environmental stimuli. It is not necessarily possible to directly assess interpretations or problem definitions because only the behavior of generating strategies and choosing a strategy to enact may be observed. Therefore, models of everyday problem solving provide constructs for interpretations and definitions that are inferred.

Sansone and Berg's (1993) process model explains that a person's definition of a problematic situation determines the way in which the person will respond, and perhaps, adapt to the environment. Sansone and Berg explain that immediately-relevant individual (age, experience, motivation, abilities) and contextual (demands, domain, culture) factors combine to influence the problem-solving process. Specifically, these working aspects of the self or context make up one's "activated life space," a subset of all global individual and contextual factors (Lewin, 1951). Crick and Dodge's (1994) information-processing model adds that after individuals interpret the situation (based on expectations about outcomes and self-ability to achieve particular outcomes), goals are developed. Then, individuals consider all possible behavioral responses (derived from memories of past experiences and/or newly conceived responses), choose the appropriate behavioral response (based on goals, expected outcomes, and self-efficacy beliefs), then enact the chosen response. Sansone and Berg (1993) point out that as individuals grow older, changes in person characteristics (e.g., perceived abilities, experience) and relevant contextual factors (aspects of daily environment) alter their problem definitions. Therefore, individual and contextual variables that change the activated life space may act as underlying mechanisms of age differences in strategy types used.

The present application of these models assumes that problem-solving strategies are the behavioral responses that may be generated based on interpretation of a situation and set of 
goals, then chosen for enactment based on some evaluation of internal characteristics and situational features. The present research assesses the degree to which person characteristics (i.e., age, gender, self-efficacy beliefs, and exposure to problems) and contextual features (domain of problem) relate to strategy effectiveness. In order to assess these factors, a methodology commonly-used in the everyday problem-solving literature is employed.

\section{Examining Problem-Solving Effectiveness}

Research in everyday problem solving has used both well- and ill-defined problems to examine performance. Well-defined problems have only one correct way to solve the problem; ill-defined problems may be solved in a number of different ways (Sinnott, 1989). Although well-defined problems provide valuable information about everyday cognition, they are often less-ecologically-valid measures of everyday performance than ill-defined problems (Denney \& Pearce, 1989). In laboratory-based tasks, participants may be asked to generate multiple potential strategies to solve hypothetical ill-defined problems or actual strategies that they have used previously in real-world problem situations (Allaire \& Marsiske, 2002; Artistico, Cervone, \& Pezzuti, 2003; Berg, Meegan, \& Klaczynski, 1999; Blanchard-Fields, Stein, \& Watson, 2004; Denney \& Pearce, 1989; Patrick \& Strough, 2004; Strough, 2004). Participants list as many strategies as possible that could solve a hypothetical problem or a real problem that the person previously encountered. These tasks allow participants to generate their own solutions to problems that they may have encountered in everyday life. Denney and Pearce (1989) stated that this approach to examining everyday problem-solving strategies may have more ecological validity than approaches that instruct participants to chose a strategy from a list (as in Allaire \& Marsiske, 1999, 2002; Berg, 1989; Blanchard-Fields, Chen, \& Norris, 1997; Cornelius \& Caspi, 1987; Marsiske \& Willis, 1995).

In order to quantify the varied strategies produced during problem-solving tasks in which participants generated multiple strategies, previous studies examined problem solving in terms of strategy fluency: the total number of strategies generated by participants (Allaire \& Marsiske, 2002; Berg et al., 1999; Strough et al., 2003). Other researchers have established more stringent strategy fluency measures: the number of unique strategies (Patrick \& Strough, 2004; Strough, McFall, Flinn, \& Schuller, 2007) or the number of safe and effective strategies (Denney, 1989; Denney \& Pearce, 1989). The safe and effective measure of strategy fluency, which assessed the degree to which a strategy is safe to employ and effective at solving the problem, suggested that 
researchers should not only consider the number of strategies, but also the quality of strategies for solving a problem. Aferall, the ultimate outcome of problem solving models, response decision, was to choose one most-effective strategy to enact in a situation (Crick \& Dodge, 1994). In the Strough (2004) study, after generating a list of strategies to solve a problem, participants selected from their list the most-effective strategy for solving the problem.

Other researchers have examined quality of strategies in several different ways, including participants' self-perceptions of strategy effectiveness (Berg, Klaczynski, Calderone, \& Strough, 1994; Berg et al., 1999), use of independent judges to rate participants' strategies (Cornelius \& Caspi, 1987; Denney \& Pearce, 1989), and use of experts to examine strategy effectiveness (Allaire \& Marsiske, 2002). The current study examines experts' ratings of individuals' selfchosen most-effective problem-solving strategies. In the section that follows, research that used independent judges or experts is reviewed. Problems within these studies are highlighted and the need for a new investigation using expert raters is discussed.

\section{Independent Judges}

Several researchers have sought out raters or judges, who are independent from designing the research study, to examine strategies produced or chosen by participants (Allaire \& Marsiske, 2002; Cornelius \& Caspi, 1987; Denney \& Pearce, 1989; Marsiske \& Willis, 1995; Smith, Staudinger, \& Baltes, 1994). Independent ratings are collected, rather than relying on participants' self-ratings of effectiveness, because self-ratings may be biased. Cornelius and Caspi (1987) suggest that people may, depending on the situation or their past experience, rely on the same strategy to solve a problem because of familiarity rather than effectiveness. Also, the use of independent raters in addition to researchers reduces the chance that effectiveness scoring simply reflects the researchers' opinions of solution competency or quality.

Researchers have various inclusion criteria for recruiting raters; types of occupation, age, and level of expertise have differed across studies. Cornelius and Caspi (1987) used a group of 23 judges to rate each of four strategy types (problem-focused action: self-action behaviors to directly deal with a problem; cognitive problem analysis: cognitive efforts to evaluate a problem from a new perspective or logically understand it better; passive-dependent behavior: withdrawing from or avoiding a problem by not initiating behaviors to deal with it; avoidant thinking and denial: cognitively avoiding the problem and denying one's involvement in it or emotional reactions) for problems from a variety of domains, including consumer, information, 
home, family, friend, and work. Of the 23 judges, 5 were the experimenters and their graduate students, while the other 18 had no psychological training. Of the 23 judges, 9 were younger adults (24-40 years old, $M=28.4$ ), 8 were middle-aged adults (44-54 years old, $M=50.3$ ) and 6 were older adults (62-72 years old, $M=67.3)$. Of the 23 judges, 13 were women and 10 were men. Judges were told to consider the likelihood that the chosen strategy would solve the immediate problem, prevent or minimize reoccurrence of the problem, and enhance self-esteem of the problem solver. They were asked to consider all three components while making one rating of a strategy's effectiveness. However, this type of combined rating has the limit of not providing the degree to which each component contributed to the efficacy ratings (Cornelius \& Caspi, 1987).

Cornelius and Caspi’s (1987) judges, in general, found problem-focused action and/or cognitive problem analysis to be the most effective strategies; passive-dependent behavior and avoidant thinking and denial strategies were judged as least effective. The ratings varied across domains and across problems within domains. In the consumer domain, for example, problemfocused action had mean effectiveness ratings from 2.57-4.78 for the eight situations and cognitive problem analysis ranged from 2.22 to 4.57 . Both problem-focused action and cognitive problem analysis were rated as more effective than the other two strategies. Problem-focused action remained high with a rating of 4.61; avoidant thinking and denial was rated 1.13.

The judges' ratings from Cornelius and Caspi (1987) have been used by additional researchers in examining everyday problem-solving effectiveness (Blanchard-Fields, Mienaltowski, \& Seay, 2007; Galambos, MacDonald, Naphtali, Cohen, \& de Frias, 2005; Marsiske \& Willis, 1995). Marsiske and Willis's (1995) study compared three measures of everyday problem solving in order to assess the dimensionality of the everyday problem-solving construct in assessing performance of older adults. One of their measures was Cornelius and Caspi's (1987) Everyday Problem-Solving Inventory (EPSI) and its original judges' ratings. Performance on the EPSI was scored by correlating Cornelius and Caspi's original judges' ratings of strategies to new participants' strategy preferences.

A second example of the use of Cornelius and Caspi's judges is the Blanchard-Fields et al. (2007) study, which examined problem-solving effectiveness for older and younger adults in three domains: interpersonal, individual, and mixed. Following Berg, Strough, Calderone, Sansone, and Weir (1998), interpersonal problems were defined as those containing social 
concerns or involving other people. Individual problems were focused on competence goals, when an individual focus on a problem that is personally relevant. Like the Marsiske and Willis (1995) study, Blanchard-Fields et al. (2007) correlated Cornelius and Caspi's (1987) judges' ratings with new participants' strategy endorsement ratings (participants' preference for problem-solving strategies) in order to form effectiveness scores. The authors found that on interpersonal problems, older adults' endorsements of each strategy type (problem-focused action, cognitive problem analysis, passive-dependent behavior, avoidant thinking and denial) were more highly correlated with experts' effectiveness ratings than younger adults'. However, for individual problems, the older adults' endorsements were only more correlated with experts' on the avoidance-denial strategy.

The use of judges' strategy ratings from Cornelius and Caspi (1987) in research conducted one or two decades later presents a problem. We cannot adequately interpret the effectiveness scores in these later studies or the conclusions about everyday problem solving because strategies viewed as effective in the mid-to-late 80 's may not be effective today. New problem-solving options may exist today that were not possible in the 80's (especially with the advances in and expansion of technology and communication networks). For example, one of Cornelius and Caspi's problem situations involves getting lost while driving a car. Today, people would say that they would use their cell phone to call for help or a service like OnStar. The use of same strategy ratings in multiple studies limits external validity and other conclusions that can be made about effectiveness. The overall body of literature, in that case, is dependent on one sampling distribution and any errors associated with that study. The present study uses newlyobtained effectiveness ratings from a group of highly-reliable raters in evaluating everyday problem-solving strategies.

\section{Expert Opinion}

Allaire and Marsiske (2002) state that it is the desire to capture some of the competent real-world judgments, or processes that allow those judgments to be made, that leads researchers to include experts as raters in their studies. Due to experience and practice in a particular field, experts develop a tacit form of knowing, which is not directly learned from instruction. This tacit knowing may be difficult to articulate, thus experts may "know more than they can tell" (Polanyi, 1967). 
In Allaire and Marsiske's (2002) study, older adult participants generated solutions to six hypothetical everyday instrumental problems (e.g., "You accidentally took the wrong combination of medication. What do you do?"). Lists of all the solutions were collapsed to eliminate redundant solutions. Experts rated the solution lists on a Likert-type scale from 1 (Least effective) to 7 (Most effective). Experts were instructed to rate solutions according to their effectiveness for solving the particular problems. Experts were told to based their ratings on their own professional expertise. Experts had to be decision makers for older adults on a daily basis and had to work in one of the following careers in order to be eligible: medicine, nursing, social work, and administration (gerontology specialists especially targeted). In determining overall solution effectiveness, experts were also encouraged to also consider solution efficiency, reduction of effort, and use of resources at hand. Forty packets were sent to potential experts, but only six completed packets were returned. All six experts were women. They ranged from 49-71 years of age $(M=58)$ and had between 17 to 20 years of education. Four of the six were social workers, one was a director of nursing, and one was a health care agency administrator.

Allaire and Marsiske's (2002) use of experts to rate solutions was an innovative approach to obtain a professional real-world evaluation of older adult's problem-solving effectiveness. The use of expert raters in this research removes the self-bias that individuals may have in examining their own problems-solving strategies. Unfortunately, the evaluation is limited in that it is based on only six raters (all women), four of which belonged to the same profession (social work). Additionally, only the individual problem domain was examined.

\section{Problem Domain}

Everyday problems occur in a variety of life domains; the content of an everyday problem influences the particular strategies that participants choose to solve the problem (Berg et al., 1998). Berg et al. (1994) and Crick and Dodge (1994) explain that one must consider contextual or situational factors, in addition to person characteristics and goals, when assessing seemingly-maladaptive responses. For example, Blanchard-Fields et al. (1995) found that older adults used more passive-dependent and avoidant-denial strategies in situations that had high emotional salience. This does not imply that older adults are deficient problem solvers. They may actually be more adaptive by managing emotional reactions rather than trying to change an uncontrollable situation (Berg et al., 1994; Blanchard-Fields et al., 1995; Sansone \& Berg, 1993). 
People choose strategies that have better fit between themselves and the particular environment of the problem situation (Berg et al., 1999). Therefore, in order to study any problem-solving task, problem content or domain necessarily must be considered. In fact, it has been included as an independent variable in many everyday problem-solving studies, has moderated which strategies are generated or nominated by participants, and has been related to those strategies' effectiveness ratings (Artistico et al., 2003; Berg et al., 1999; Berg et al., 1998; Blanchard-Fields et al., 1997). Examples of several domains and strategies follow.

Berg et al. (1998) examined individuals' problem-solving strategies for a variety of problem domains. Participants were asked to first describe any problem that they had experienced (regardless of domain). Then participants were asked to describe a problem that they had previously encountered in one of the following domains (constrained domain randomly assigned): family, friends, health, school, work, leisure. Problem definitions, which are domainspecific and based on the individual's subjective experience of the problem situation, were the best predictors of the type of strategy described. This effect was found for both unconstrained and constrained-domain problems. When health or school problem domains were specified, individuals demonstrated competency concerns. These competency concerns were less likely to result in regulation or inclusion of others and more likely to include self-regulation strategies. Problems in health and school, that generate competency concerns, are more relevant to the individual's goals.

Individual problems do not have the social-emotional content found in interpersonal problems (Allaire \& Marsiske, 2002). Friend and family problems are social problems, which can be grouped in an interpersonal domain (Berg, Strough, Calderone, Meegan, \& Sansone, 1997; Blanchard-Fields et al., 1997; Cornelius \& Caspi, 1987). In the Berg et al. (1998) study, the authors reported that, among problems identified as having interpersonal content, strategies such as including or regulating others were likely to be reported. The interpersonal-individual problem domain distinction is especially important when one considers age of the problem solver. In Blanchard-Fields et al. (1995), for example, older adults generated more avoidantdenial and passive dependent strategies than younger adults; the difference was most striking for an interpersonal domain - the friend domain - which may have this social-emotional content.

Knowing which strategies are used in various domains is important. However, this information does not explain whether or not the differences are necessarily important. The 
evaluation of the effectiveness of a strategy, on a domain by domain basis, provides a means to understanding how people adapt to their environment. Cornelius and Caspi (1987) found external judges' effectiveness ratings of strategies to differ across situations within consumer, work, information, home, family, and friend domains. The current study examines how strategy effectiveness differs between the commonly-studied interpersonal and individual problem domains. Also of interest are age-related differences in effectiveness within problem domains.

\section{Age-Cohort Differences}

Crick and Dodge (1994) and Sansone and Berg (1993) suggest a second moderator that affects information processing and problem solving: age of the individual. Numerous studies have examined age differences in everyday problem solving (Artistico et al., 2003; Berg, 1989; Berg et al., 1994, 1997, 1998, 1999; Blanchard-Fields et al., 1997, 2004, 2007; Cornelius \& Caspi, 1987; Denney \& Pearce, 1989; Thornton \& Dumke, 2005). Problem-solving strategy choice has been consistently shown to be moderated by age (Berg, et al., 1998; Blanchard-Fields \& Camp, 1990; Blanchard-Fields, Jahnke, \& Camp, 1995) and age has been shown to interact with the domain of the problem (Berg et al., 1998; Blanchard-Fields et al., 2007). In early problem-solving research, strictly scoring procedures for strategies may not have accounted for differing goals or interpretations that may occur with individuals' advanced age (Marsiske \& Margrett, 2006). Therefore, previous researchers may not have recognized that simple differences in strategy use are not equivalent to differences in adaptive responding. To capture these changes, researchers have examined age differences in strategy effectiveness (BlanchardFields et al., 2007; Cornelius \& Caspi, 1987).

Older adult participants in the Blanchard-Fields et al. (1995) study used problem-focused strategies less than adolescents, young adults, and middle-aged adults. The use of problemfocused strategies also decreased as emotional salience of the problem increased. The strategies that increased with higher emotional salience were cognitive analysis by younger adults and passive-dependent behavior by older adults. Older adults used avoidant-denial strategies more than other age groups in low emotion problems. Blanchard-Fields and Camp (1990) also found that emotional salience moderated age differences in problem-solving strategies. In problems with low emotional salience, like individual problems, no age differences were found. However, for problems with high emotional salience, such as an interpersonal problem about family, older adults used strategies in a more diverse manner. They were willing to use various strategy types, 
depending on the problem content, unlike young adults who only used problem-focused or cognitive analysis solutions.

Blanchard-Fields et al. (2007) found strategy effectiveness to differ based on an age by domain interaction: older adults were more effective than younger adults in their strategy choice for interpersonal problems. In general, both age groups had higher effectiveness scores for instrumental and mixed-domain problems than for interpersonal problems. Further exploration of strategy effectiveness scores revealed that older adults were more likely to be consistent (consistent endorsements occur when the problem solver endorses strategies that were rated as more effective by experts for the situation and does not endorse strategies that were rated as less effective) with judges in endorsing avoidance-denial and cognitive analysis strategies for interpersonal problems. Older adults were also more consistent with judges when endorsing avoidant-denial strategies for individual problems. These findings suggest that age and problem domain may be important for understanding strategy effectiveness in the current research, favoring older adults' strategies for solving interpersonal problems.

\section{Gender}

A third potential moderator of strategy effectiveness, gender of the individual, has been examined in everyday problem-solving studies, usually accompanied by age and/or domain. Gender is another individual characteristic that may influence the interpretation of a problem (Sansone \& Berg, 1993). There have, however, been inconclusive results in assessing gender differences in everyday problem solving. Several studies have found no gender differences in strategy use. Denney and Pearce (1989) examined age, sex, and experimenter's sex on performed assessed by fluency of safe and effective strategies; only a main effect of age was significant. Blanchard-Fields et al. (1995) found no gender differences in their study on age, gender, emotional salience of problems, and problem-solving styles.

The gender effect may actually have more to do with dealing with the emotional reaction to a problem rather. Blanchard-Fields et al. (2004) asked participants to describe two problem situations that they had recently encountered; one problem was supposed to be very emotional, while the other was supposed to not be very emotional. Participants were instructed to list strategies they used to solve the problem and strategies they used to deal with the emotional reactions that they had experienced. Although no gender differences were found in strategies used to solve problems, gender was the only significant main effect when looking at the 
strategies people used to deal with emotional responses. Overall, women used more emotion regulation strategies than men. Additionally, for problems that had low emotional salience, women of all ages were more likely to use proactive emotional regulation strategies than men. At levels of high emotional salience of the problem, no gender differences existed in strategy type used.

Alternatively, in Blanchard-Fields et al. (1997) there was a significant Gender X Domain (home, friend, and consumer) X Problem-Solving Strategy interaction in participants' ratings of how likely they were to use each strategy type. Gender differences were found: women were more likely than men to endorse cognitive analysis and passive-dependent strategies in the consumer domain; women endorsed more passive-dependent strategies in the home domain; and in the friend domain, women endorsed more cognitive analysis and problem-focused strategies.

Perhaps gender differences arise out of differences in expression of emotion, or more specifically, in differential choice of problem-solving strategies for domains that vary in terms of emotional salience. Allaire and Marsiske (2002) describe interpersonal problems as having social-emotional content. If differences do exist for men and women in use of strategy types for interpersonal versus individual problems, then effectiveness ratings should differ for men and women, assuming that different strategy types are differentially rated as effective. Watson and Blanchard-Fields (1998), for some analyses, used a coding scheme that included the four Cornelius and Caspi (1987) strategy types. They found more gender differences in strategy endorsement for interpersonal problems: women were more likely than men to seek help and experience negative feelings; women were less likely to be confrontive or self-centered (Watson \& Blanchard-Fields, 1998).

Among the everyday problem-solving studies that have examined gender, very different results have been uncovered based on the methodology used in the research. What seems continuous across several studies, though, is more variability of strategies used in interpersonal problems (that may contain socio-emotional content) for men and women (Watson and Blanchard-Fields, 1998). Inconsistencies in gender differences among everyday problem-solving studies may also reflect differences in the categorical schemes for examining strategies or situational differences of problems. Some existing studies that used few strategy types when assessing gender differences may not capture the types of behaviors that differ by gender. In the present study, specific strategies are examined by expert raters, rather than categories of strategy 
types. Additionally, age differences in specific strategy use by gender may be uncovered for each domain.

\section{Exposure to Problems}

Although age differences in problem-solving strategy selection and effectiveness have been outlined in prior literature, the present study seeks to explain what it is about age that leads to differences for younger and older adults in everyday problem solving. In this sense, age might act as a proxy variable for other age-related variables. One possible age-related explanation for age differences in everyday problem solving is exposure to the particular problems. At any particular time in the life span, individuals may be exposed to certain situations more often than at other times. Over the course of a life time, exposure to problems may relate to a sense of experience with problem solving. Greater experience with problem solving may lead to better problem solving (Baltes, Dittmann-Kohli, \& Dixon, 1984; Denney, Pearce, \& Palmer, 1982). Salthouse's well-known (1984) study examined skilled typists' speedy performance on typing tests, compared to less-experienced typists. Although older, more experienced typists had lower reaction time than younger typists, a possible age-related decline, the older typists were more efficient than the younger typists. Greater experience with typing allowed the older individuals to learn ways of being more efficient. For example, experience typists were able to overlap the many cognitive operations involved in typing; much more time was saved by overlapping cognitive operations than was lost by slowed reaction times.

During everyday problem solving, greater exposure may provide more opportunities for an adaptive process to occur, as in Sansone and Berg's (1993) model. Given this model, exposure is expected to be domain specific. Blanchard-Fields et al. (1997) examined familiarity with various problems for five age groups ranging from adolescents through older adults. Domains included problems relative to friends, home, and being a consumer. In the home domain, younger adults were more familiar with the problems than older adults. All age groups were more familiar than older adults in the friend domain. In the current study, exposure to problems will be examined as a mediator of any age differences that occur for problem-solving effectiveness.

\section{Self-Efficacy Beliefs}

Why might age, gender, or domain differences exist? Individuals may have varying degrees of beliefs in their abilities to solve problems, which may influence generation and choice 
of strategies (Crick \& Dodge, 1994; Sansone \& Berg, 1993). D’Zurilla et al. (2004) present a model of problem solving outcomes in which self-efficacy beliefs are part of an individual's problem orientation (appraisal of problem, expectations, beliefs about problem solving). The problem orientation directly determines which types of strategies the person will employ. Specifically, a positive orientation (high self-efficacy) will result in a problem solving style in which people define the problem, generate options, choose a response, and implement the strategy. This track of problem solving is considered "constructive" and has positive outcomes. A "dysfunctional" track involves negative problem orientation (low self-efficacy) that results in careless, impulsive, or avoidant strategy use and negative outcomes.

During everyday problem solving, self-efficacy beliefs may act as a mediator of strategy effectiveness for various problem situations; however, existing everyday problem-solving literature has not adequately addressed this mechanism (Marsiske \& Margrett, 2006). One study has examined self-efficacy beliefs as mediators of differences in age group and performance on problem-solving tasks (Artistico et al., 2003). Younger and older adults had higher general selfefficacy scores for problems that were relevant to their respective age groups. In regards to performance, older adults generated more solutions than younger adults for the problems relevant to older adults; younger adults outperformed older adults on the younger adult problems and common problems. Self-efficacy beliefs were shown to partially mediate the relation between age group and performance for problems relevant to younger or older adults; age differences for common problems were not accounted for by self-efficacy mediation.

The domain of a problem and gender of participant may also be related to self-efficacy. In Blanchard-Fields et al. (1997), main effects of age and gender were qualified by a significant interaction when assessing participants' perceived ability to resolve the home domain situation. Of men, adolescent boys had the lowest perceived ability than all other age groups. In the home domain, older women had the lowest perceived ability. Men had lower efficacy scores than women in the consumer domain. In the friend domain, greater perceived ability to solve the problem was related to more use of cognitive analysis strategies. In general, perceived ability to solve the problem was a significant predictor of strategy endorsement. Higher self-rated ability was always related to lower endorsement of avoidant-denial strategies, for individual and interpersonal problems. 
In Allaire and Marsiske's (2002) study, the relation of problem-solving solutions to everyday functioning was examined. They assessed older adult participants' self-ratings of everyday instrumental functioning in terms of independence in completing cognitively-complex daily living tasks and perceived ability in performing the tasks. Solution fluency was not a significant predictor of functioning; solution quality (efficacy of solutions as assessed by experts), though, did predict everyday instrumental functioning. In the current study, the relation of self-efficacy beliefs to strategy effectiveness for older and younger adults is examined through mediation analysis.

\section{Statement of the Problem}

The strategies that individuals choose to solve everyday problems vary by problem domain and the gender of the problem solver (Blanchard-Fields et al., 1995; Blanchard-Fields \& Camp, 1990). Current research that uses Cornelius and Caspi's (1987) judges' ratings of strategy effectiveness suggests that effectiveness of strategies also varies by age and domain (BlanchardFields et al., 2007). However, results are based on 20 -year-old ratings, which may not accurately represent effectiveness of strategies today. In addition, gender differences in everyday problem solving have been inconsistent across studies (Blanchard-Fields et al., 1995, 1997; Denney \& Pearce, 1989), but may depend on problem content (Blanchard-Fields et al., 1997, 2004). The specific aim of the present study is to determine whether the effectiveness of younger and older adult men and women's choices of strategies, as rated by experts, differs during interpersonal and instrumental everyday problem solving.

\section{Research Questions and Hypotheses}

\section{Research Question 1}

Do the strategies generated by older and younger adult men and women for solving interpersonal and instrumental everyday problems differ in terms of effectiveness as rated by experts?

Hypothesis 1. A three-way interaction of Age X Gender X Domain on strategy effectiveness scores is expected. Strategy effectiveness will differ on the interpersonal problem according to a two-way interaction of age and gender, but strategy effectiveness will not differ according to age or gender on the instrumental problem. Specifically for the interpersonal problem, older adults' strategies are expected to have higher effectiveness ratings (experts' average ratings of participants' self-chosen most effective strategies) than those generated by 
younger adults for the interpersonal problem. This age difference is expected to be more pronounced for men than women. This hypothesis is based on research that has indicated greater differences in strategy choice or effectiveness for interpersonal problems than instrumental problems; during interpersonal problem solving, older adults used strategies in a more diverse manner depending on content of the problem as well as more effective strategies (BlanchardFields et al., 1990, 1995, 2007).

\section{Research Question 2}

If interaction effects or main effects are found in the first research question, do selfefficacy beliefs for solving everyday problems or exposure to everyday problems account for the group differences in strategy effectiveness?

Hypothesis 2. Self-efficacy is expected to be at least a partial mediator of significant age or gender differences in effectiveness scores. Artistico et al. (2003) found self-efficacy beliefs to be a partial mediator of age differences in problem-solving task performance. The mediation of gender differences is more exploratory since self-efficacy has not yet been examined as a mediator of gender differences in everyday problem-solving performance. However, BlanchardFields et al. (1997) examined the relation of self-efficacy beliefs to strategy types used by participants. A significant interaction was found for participants' perceived ability to resolve an instrumental problem. Of men, adolescent boys had the lowest perceived ability than all other age groups. In the home domain, older women had the lowest perceived ability. Men had lower efficacy scores than women in the consumer domain.

Hypothesis 3. Exposure to everyday problems is expected to be at least a partial mediator of significant age or gender differences in effectiveness scores. This hypothesis is based on research by Blanchard-Fields et al. (1997), in which age differences were found for home and friend domain everyday problems. 
Method

Design

The present study utilizes two sources of data: existing everyday problem-solving strategies (Strough, 2004) and a new data collection of strategy effectiveness ratings. The design is a 2 X 2 X 2 mixed-model approach: problem domain (interpersonal, instrumental) is a withinsubjects variable; age (older adult, younger adult) and gender (men, women) are betweensubjects variables. The dependent variable is overall strategy effectiveness scores, which are derived form experts' average ratings of participants' self-chosen most effective strategies. Selfefficacy beliefs and exposure to everyday problems are potential mediators of significant group differences in strategy effectiveness due to age and/or gender.

\section{Participants}

\section{Younger and Older Adults}

Data for the present study were drawn from Strough's (2004) study, "Collaborative everyday problem solving: Gain or loss?" As part of the NIH-funded study of everyday problem solving and collaboration, younger (age 18-25) and older (age 60+) adult participants generated solutions to interpersonal and instrumental everyday problems (Strough, 2004). Participants were required to bring a same-sex friend to the data collection session in order to examine collaboration via a dyadic design. Half of the friend pairs collaborated (worked together) while completing the problem-solving tasks; these were called interacting dyads. The remaining dyads (nominal pairs) served as a control condition; they worked separately. In this nominal versus interacting dyadic design, the only difference between conditions was presence or absence of interaction, so that interactive collaboration could be examined systematically (Strough, 2004). The present study uses data from the nominal pairs who completed the problem-solving tasks alone.

A total of 148 adults were assigned to the nominal pairs condition in Strough' (2004) study: 74 younger adults (ages 18-27, Mage $=19.45$ years, $S D=1.37$ ) and 74 older adults (ages $58-91$, Mage $=74.15$ years, $S D=8.11$ ). For the current study, interacting pairs were excluded because their individual contributions could not be separated. A power analysis, conducted using the GPower software (Erdfelder, Faul, \& Buchner, 1996), demonstrated that a sample size of $N=$ 128 is sufficient (power $>.80$ ) to detect medium-sized effects $(f=.25)$ in a second-order interaction. 
Among the individuals assigned to the nominal condition, younger adult participants were recruited from undergraduate psychology classes at West Virginia University; older adults from West Virginia (56\%) and Pennsylvania (44\%) were recruited from senior centers, community groups, and phone invitations. Younger adults' permanent residences included West Virginia (50\%), Pennsylvania (20\%), New Jersey (11\%), Virginia (8\%), Deleware (4\%) and several other states (7\%). Approximately $93 \%$ of the 148 individuals included in the current study were Caucasian. Younger adults (36 men, 38 women) had all never been married. Older adults ( 22 men, 52 women) had more diverse marital backgrounds consisting of presently being married (35\%), being widowed (47\%), being divorced (14\%), never being married (1\%), or other marital status (3\%). Younger and older adults did not differ in mean years of education: younger adults had between 12 and 18.50 years of education $(M=13.58, S D=1.25)$ and older adults had between 8 and 30 years of education $(M=13.62, S D=3.14), t(1,146)=0.10, p=.92$. Experts

In the present research, new data were collected in order to gather a sample of expert raters of everyday problem-solving strategies. Professionals from fields that contained gerontology specialists or younger adult specialists were targeted for recruitment, especially social work and counseling (see Allaire \& Marsiske, 2002). Unlike Cornelius and Caspi (1987), academic experts were excluded in order to ensure that the data were not influenced by the current literature on everyday problem-solving strategy effectiveness. Allaire and Marsiske (2002) received ratings from only women; the present study attempted to recruit a diverse expert panel by targeting both women and men professionals. In order to ensure appropriate expertise of expert participants, the following inclusion criteria were required: current employment in one of the above fields and at least five years of experience in one of those fields (Allaire \& Marsiske, 2002). Since the sample of adults in the Strough (2004) study were half older adults and half younger adults, efforts were made to recruit professionals of all adult ages. Allaire and Marsiske (2002) received data from six raters; Cornelius and Caspi (1987) utilized 23 judges. A very important issue when collecting expert raters is not necessarily the number of raters, but their agreement or reliability. The present study sought a number of highly reliable experts that produced an alpha of at least .80 .

Seven professionals (six social workers, one counselor) rated the effectiveness of the strategies generated by older and younger adult participants. Of the seven, five were women and 
two were men. The professionals ranged in age from 26.17 to 62.92 years $(M=44.15, S D=$ $12.61)$ and all met the minimum five years of expertise $(M=16.00, S D=11.11)$. The reliability of the seven experts' ratings reached an alpha of .94. Reliability was performed by treating each expert as a "scale item" and by treating the expert's ratings of the three dimensions of strategy effectiveness for each strategy as cases. The high reliability suggests that the ratings of the seven experts are appropriate for combining.

In order to determine whether the sample of professionals that met inclusion criteria was a more ecologically-valid group of expert raters than a group of non-professionals, a comparison group of seven college students completed the same online survey measures as did expert participants. They ranged in age from 19.50 to 22.13 years $(M=20.92, S D=$ 1.02) Five students were women and two students were men. The students' reliability reached an alpha of .90. See Preliminary Results section for tests of differences in strategy effectiveness ratings due to expertise.

\section{Procedure}

\section{Younger and Older Adults}

As part of Strough's (2004) study, older and younger adult participants completed a written demographics questionnaire, interpersonal and instrumental problem-solving tasks, selfefficacy measures, and a variety of other measures. Only those measures relevant to the current report are described here. All younger adult participants completed measures in the laboratory. The majority of older adult participants (88\%) completed the measures in the field (i.e., at home, in a senior center). Some older adults participated (12\%) completed the measures in the laboratory. The difference in task setting for younger and older adults was not expected to influence the results of the current study. Younger adults were primarily college students who spend majority of their weekday time in academic buildings, such as the building where the Strough laboratory is located; older adults often spend time in senior centers or living facilities, where their data was collected.

Younger and older adult participants were instructed, prior to completing the problemsolving task, to list as many strategies as they could generate. Participants were asked to then mark the one strategy that they believed to be most effective in solving each problem. The experimenter gave the participants an example problem (i.e., "You are driving and your car breaks down. What do you do?") and prompted participants to verbally generate strategies to 
solve that problem. Then, participants completed measures of exposure to the problems, judgment and decision-making tasks, and a variety of other measures related to their goals during task completion and interaction with their friend. After completion of all measures, the experimenter asked younger adult participants whether they would rather receive extra credit in a psychology class or a $\$ 20$ honorarium in return for their participation. All older adults received the \$20 honorarium. Of the 146 undergraduates who participated in the Strough (2004) study, 66 received extra credit, while the remaining 80 received an honorarium (see Preliminary Results section for tests showing that the honorarium choice did not influence performance). After data collection, strategies were transcribed into word processing documents on laboratory computers by undergraduate research assistants, then checked and double-checked for accuracy. Later, strategies were classified via a coding scheme (see Strategy Coding section). Experts

Expert participants completed tasks via an online survey. The online survey included the demographics questionnaire, additional questions about expertise in solving everyday problems, and lists of strategies generated by older and younger adults in Strough's (2004) study which the experts rated. The web-based data collection program allowed for convenient participation. Additionally, each expert participant was given a $\$ 10$ honorarium in return for completing the survey. Using a different type of data collection method (online) than the paper and pencil questionnaires given to older and younger adults is not of concern because experts were providing ratings of strategies and not acting as a comparison group.

Individuals who met inclusion criteria as experts (verified through phone/e-mail) received a password via e-mail which allowed them to login to the online survey; this prevented nonexperts from taking the survey. For each problem-solving task, experts were presented with strategies that were representative of those generated by older and younger adult participants (see Measures section). They used three rating scales to judge the effectiveness of each strategy: the first scale addressed the degree to which the strategy would solve the problem, the second assessed the extent to which the strategy would prevent or minimize future occurrences of the problem, and the third examined the degree of safety for a person to employ that strategy (Cornelius \& Caspi, 1987; Denney \& Pearce, 1989). Scores on the three rating scales were averaged to form an effectiveness rating for each strategy. Using three component scores to assess efficacy allowed for post-hoc examination of how each component contributed to the 
expert' efficacy ratings, which was not possible with prior methodology used in Cornelius and Caspi (1987) and Allaire and Marsiske (2002).

\section{Measures}

\section{Demographic Information}

Older and younger adult participants first completed demographic questions about sex, age, race, education (number of years and highest degree earned), marital status (and duration), income, living status, work status (current status, type of work of longest duration, type of workplace), and Lawton, Moss, Fulcomer, and Kleban's (1982) Perceived Health scale (current rating, change over past 3 years, compared with others) via a selfreport demographics measure (see Strough et al., 2002). Experts also first completed the same questions, but via an online survey. The demographics questionnaire items are included in Appendix A. Additional items were asked of expert participants in order to obtain demographic information about professionals' expertise in everyday problem solving (e.g., type of experience, years of experience, etc). See Appendix B for a list of the questions for assessing expertise.

Perceived Self-Efficacy Beliefs.

Older and younger adults completed two measures of perceived problem-solving self-efficacy as part of their participation in Strough's (2004) study, from which data for the present investigation were drawn. The scales were created and used in Strough et al. (2002). Each measure consisted of nine items that were combined via averaging. The first measure assessed one's perceived problem-solving ability as compared to others of the same age. For example, "Compared with most people your age, would you say your ability to solve everyday problems is...." Each item was followed by a set of three response choices: "Better," "The Same," "Not as good?" Originally, lower scores represented better ability compared to others the same age. Data were recoded in order to improve interpretability, such that higher scores represented better ability. See Appendix $\mathrm{C}$ for a list of all nine items. The nine items were internally consistent $(\alpha=.72, N=142)$.

The second measure assessed change in one's perceived ability to solve everyday problems as he or she had gotten older. For example, "As I have gotten older, my ability to solve everyday problems has...." These nine items mirrored the content of the items in the first self-efficacy scale (see Appendix D). The response choices were "Improved," "Not 
Changed," and "Declined." Again, lower scores originally represented improved ability; data were recoded so that higher scores represented improvement in ability. This scale had an alpha of $\alpha=.90, N=145$ ).

For creation of the two self-efficacy scales, if one to three items were missing (up to $33 \%$ of the scale items), the mean response for the individual was substituted for the missing item(s). This is a more stringent and conservative criteria for data imputation than imputing scale scores for scales that have up to $50 \%$ of scale item values missing. The means were imputed in two cases. For more than three missing values in either scale, then no score was computed and the participant was excluded from the particular analysis (occurred four times for the first scale and once for the second scale). Everyday Problem-Solving Vignettes

As part of Strough's (2004) study, older and younger adults were presented with interpersonal and instrumental problem vignettes (total of seven). The problem vignettes were drawn from the everyday problem-solving literature, specifically Cornelius and Caspi's (1987) Everyday Problem Solving Inventory. Cornelius and Caspi (1987) included problems that were relevant to younger, middle-aged, and/or older adults. The Strough (2004) study chose those problems that were seemingly relevant to both younger and older adults (see Exposure to Everyday Problems section for the percent of younger and older adults who did have exposure to these problems).

Four of the seven problems were central to the Strough (2004) study. Two of the remaining three problems (one interpersonal and one instrumental problem) were used in the current study. The two problems that were selected better represent their respective domains than the third problem, which may have contained both instrumental and interpersonal (mixed) components. The following are the two hypothetical problems of interest in the present investigation:

Interpersonal problem vignette. "You are with a group of people who begin gossiping about one of your friends. What do you do?"

Instrumental problem vignette. You have a limited income. You don't have enough money to pay your bills. What do you do?"

Self-chosen effective strategies. Younger and older adult participants were instructed to generate an exhaustive list of strategies after reading each problem vignette. 
They were instructed to then select the one strategy for each problem that they believed to be the most effective solution and mark it with an " $\mathrm{X}$ " (Strough, 2004). A participant's self-chosen effective strategy often differed for the two problems, as would be expected. For example: on the gossip problem (interpersonal), participant 117 chose "walk out of there" as the most effective strategy to solve the problem; for the limited income problem (instrumental), the participant chose "don't spend as much" as the most effective strategy.

Strategy coding. Self-chosen effective strategies were assigned a strategy code as part of Strough's (2004) study. The strategy classification was developed and modified by Strough and colleagues (Strough, McFall, Flinn, \& Schuller, 2007; Strough, Patrick, \& Swenson, 2003; Swenson, 2003). The classification scheme consisted of 15 strategy codes. Eight strategy codes were problem-focused: two of which were oriented toward changing one's own behavior (i.e., behavioral inhibition, self-action), one strategy was a form of cognitive analysis (i.e., deliberation), three were constructive interpersonal strategies (i.e., discussion, seeking instrumental support, self-assertion), and two strategies were socially inappropriate, destructive acts (i.e., aggression, verbal aggression). Six strategy codes were emotion-focused: two of which were proactive strategies to regulate one's subjective experience (i.e., accepting influence, emotion regulation) and four strategies were passive (i.e., doing nothing, ignoring the problem, leaving/disengaging, passive acceptance). The last code was used for other strategies that do not fit in the above categories (see Appendix E for the coding scheme).

How were participant 117's strategies coded? The "walk out of there" strategy was a form of leaving/disengaging; "don't spend as much” was a form of behavioral inhibition. Exposure to Everyday Problems

After participants completed the everyday problem-solving tasks, they were asked two questions about each problem vignette. The first question asked whether the person had ever experienced a problem like that before. Participants circled either "yes" or "no." The majority of participants reported experience with the gossip problem ( $97 \%$ of younger adults, $75 \%$ of older adults, $100 \%$ of experts). Slightly less than half of participants reported experience with the finance problem ( $41 \%$ of younger adults, $46 \%$ of older adults, $71 \%$ of experts). The second question followed-up an affirmative response on the first question: "How often do you experience this problem?" Participants selected a response on a seven-point scale ranging from "1" (every few years) to "7" (everyday). The two 
questions for each vignette were combined into an eight-point scale by adding a " 0 " to the "how often" scale if the answer to the first question was "no."

Strategy Ratings

Expert participants, as part of the present study, were also presented with the seven vignettes used in the Strough (2004) study. Each vignette was followed by a list of representative strategies that were selected as most effective by older and younger adult participants. Experts rated each of these strategies on three separate dimensions. Then the ratings of the three dimensions were averaged into strategy effectiveness ratings. Finally, the effectiveness ratings obtained from the seven experts were averaged, creating overall strategy effectiveness scores.

Representative strategies. The strategies that older and younger adults designated as most effective consisted of many similar or almost identical strategies. For the purposes of the present research, the self-chosen effective strategies were combined to create composite, more-global strategies, which encompassed the minor differences, but did not change the general meaning of the strategies. This reduced redundancy in the group of strategies that were rated by the experts. For example, rather than asking experts to rate three practically equivalent strategies ("leave the group," "walk away form the situation," and Participant 117's "walk out of there") one representative strategy, "leave the group" was rated by experts. A similar procedure was used by Allaire and Marsiske (2002), who eliminated all redundant solutions on their everyday cognition measure and sent the lists of remaining solutions to experts for rating.

An independent individual who was also reliably trained to use Strough et al's (2007) coding scheme was asked to examine the full and representative lists. If the independent rater believed that a representative strategy did not adequately represent the corresponding strategy category in the full list, then the investigator and independent rater discussed and came to consensus on how to resolve the discrepancy. A total of 26 representative strategies were identified: 17 for the gossip problem and 9 for the finance problem (see Appendix F for a list of the representative strategies). Additional "distracter" strategies were inserted into the lists of representative strategies in order to ensure that the two lists of strategies to be rated were similar in terms of length and content (recall that the finance problem list had fewer strategies than the gossip problem list). Experts rated a total 
of 21 strategies for each of the two problems. The order of strategies within each list was randomly determined via random number generator. In order to control for order effects due to which problem's list of strategies was rater first, two counterbalanced versions of the strategy rating measure were used. Participants were randomly assigned to either receive the gossip problem list before the finance problem's list or the finance problem list before the gossip problem's list.

Strategy effectiveness ratings. An effective strategy, according to D'Zurilla, Nezu, and Maydeu-Olivares (2004), is one that meets the problem-solving goal while maximizing other beneficial consequences and minimizing potential negative consequences. Experts in the current study used seven-point rating scales from 1 (least effective) to 7 (most effective), derived from Allaire and Marsiske (2002), to rate each of three effectiveness dimensions of the representative strategies for each problem. The three dimensions, drawn from Cornelius and Caspi (1987), complement D'Zurilla and colleagues' definition of strategy effectiveness. The first dimension, the degree to which the strategy would solve the problem, assessed whether the strategy "meets the problem-solving goal." The second dimension, the degree to which the strategy would prevent or minimize future occurrences of the problem, assessed "maximizing other beneficial consequences" to strategy enactment. The third dimension, the degree to which the strategy would be safe for a person to employ, assessed the "minimizing potential negative consequences" of strategy enactment. Experts were instructed to rate each of these dimensions as it pertained to effectiveness of the strategy as determined by their expertise. Each expert's three effectiveness ratings (one for each of the three effectiveness dimensions) for each strategy were averaged in order to form effectiveness scores for each strategy by each expert.

The representative strategy, "leave the group," for example, received the following ratings from Expert 7 on the three dimensions: " 2 " for effectiveness in solving the problem, " 1 " for effectiveness in preventing future occurrence, and " 6 " for safety. The effectiveness score for this strategy by Expert 7 would be " 3 " [(2+1+6)/3].

Occasionally, a participant's most self-chosen effective strategy was a combination of two or three separate strategies (separated by "and," "but," or a new sentence). In this case, the individual components of the combined strategy were evaluated separately and the highest of the component ratings was used as the effectiveness rating for that participant. 
This procedure ensured that all participants had only one strategy rating for each problem and that the strategy was their one most-effective strategy.

Overall strategy effectiveness scores. Expert ratings resulted in effectiveness scores for each strategy corresponding to each problem. For each strategy, the seven experts' effectiveness scores were averaged to form an overall strategy effectiveness score for each strategy for each problem. Then, the overall strategy effectiveness scores were substituted for each participant's self-chosen effective strategy. For example, the average of all seven experts' effectiveness scores for "leave the group" was 4.10; "4.10" was substituted for Participant 117's "walk out of there." This allowed for quantitative analyses to be performed with overall strategy effectiveness scores as the dependent variable. Tables 1 and 2 list the overall strategy effectiveness ratings for each strategy and the percent each strategy was chosen by younger and older adults for the gossip and finance problems, respectively.

\section{Independence of Observations}

Pairs of friends participated in the Strough (2004) study; therefore, each of the 132 nominal condition individuals included in the current research was linked to one other individual in the sample, but not necessarily the rest of the participants. These friendship links potentially add dependency within the data due to friendship because friends may or may not have had more similar scores to one another than any other random participant. Many statistical tests assume independence of data. In order to assess dependency in quantitative measures, one-way random average-measures intra-class correlations were performed across the friend dyads making up the older and younger adult participants (Griffin \& Gonzalez, 1995; Howell, 2002). Each scale (exposure to the gossip problem and finance problem, ability compared to others, change in ability as one gets older) was computed for the first person of the dyad and also for the second person in the dyad. Then, the two subscales were assessed for agreement. In order to examine similarity of dyad members' choices of most-effective strategies, kappas were computed on the strategy codes. A significant interclass correlation or kappa $(p<.05)$ would mark the presence of dependency between pairs of friends for that scale. Intra-class correlations range from zero to one and are interpreted similarly to other measures of reliability (e.g., alpha) (Howelll, 2002). See Preliminary Results section for non-independence tests. 


\begin{abstract}
Analyses
The first research question was examined by a 2 (problem domain) X 2 (age) X 2 (gender) repeated-measures univariate ANOVA, which examined group differences in the dependent variable, overall strategy effectiveness scores. Problem domain was a within-subjects variable; age and gender were between-subjects variables. The second research question was addressed in order to explain significant group differences in overall effectiveness scores in the first research question. Path analyses, using AMOS 16.0 were conducted in order to test mediation models. The potential mediators of group differences in strategy effectiveness scores were the two subscales of perceived self-efficacy beliefs and the exposure scales for the two problems. Mediation was only assessed if the potential mediators were significantly correlated to both the predictor and outcome variables. Therefore, Pearson correlations were computed prior to path analyses. Mediation was present if all or part of the direct effect of the exogenous predictor (i.e., age, gender, domain, or interaction) on the endogenous variable (i.e., overall strategy effectiveness score) was transmitted to the intervening variable (i.e., self-efficacy beliefs, exposure to problems) (Kline, 2005, p. 128).
\end{abstract}


Results

\section{Preliminary}

Expertise

In order to examine mean differences in the ratings of the 26 strategies due to expertise, independent samples $t$ tests were performed on the average strategy effectiveness rating scores. There were significant mean differences in average strategy effectiveness ratings between expert and student raters on two of the 26 strategies included in the present study (students rated the effectiveness of the gossip problem strategy, "Listen to what they're talking about," and the finance problem strategy, "Do things that will increase your income," higher than did experts. In order to see whether experts and students used the dimensions of effectiveness similarly for the two problems, a 2 (expertise) X 3 (dimension) repeated-measures ANOVA was performed on the effectiveness ratings. Expertise was the within-subjects variable; dimension was the betweensubjects variable. Both main effects were significant, interactions were nonsignificant. The main effect of expertise revealed that students tended to rate strategies higher $(M=3.97, S E=0.16)$ than did experts $(M=3.82, S E=0.16), F(1,78)=5.00, p<.05$. The main effect of dimension suggested that strategy dimensions were differentially influential in determining strategy effectiveness, $F(2,78)=4.73, p<.05$. Post-hoc multiple comparisons revealed that the degree to which strategies were safe to employ tended to be rated significantly higher than the degree to which the strategy would solve the problem, $p<.05$, and the degree to which the strategy would prevent future problems, $p<.01$.

\section{Non-independence}

Perceived self-efficacy beliefs. Four intra-class correlations were computed: the two subscales of self-efficacy for younger adults and the two subscales for older adults. All averagemeasures intra-class correlations were nonsignificant $(p>.05)$, but ranged from .12 to .45 .

Exposure to everyday problems. Intra-class correlations between friend pairs for exposure to the gossip problem and exposure to the finance problem were .25 and .24 , respectively. Neither scale was significant $(p>.05)$.

Most-effective strategies codes. For each problem, kappas were computed to assess the level of dependency between each person of the nominal pair in choice of most-effective strategies. A kappa is a measure of agreement. In the present analysis, a kappa answers the question, to what extent does the first person in each nominal pair tend to select the same 
strategy as the second person in each pair? Therefore, a kappa is computed for each strategy code of the coding scheme described above for each problem. For the gossip problem, none of the eight strategy types were similarly chosen within dyads; for the income problem, one of the four strategy types had a significant kappa (kappa $=.23, p<.05)$, suggesting that members of the friend dyads similarly used the behavioral inhibition strategy. In general, the self-chosen effective strategies for both hypothetical problems, according to their corresponding code on the Strough et al.'s (2007) coding scheme, were independent observations.

\section{Honorarium}

In order to assess whether younger adults' choice of honorarium (either the $\$ 20$ or extra credit in a psychology class) influenced the dependent variables, an independent samples $t$ test was performed on each of the two overall strategy effectiveness score variables. Both the test for the gossip problem, $t(72)=0.59, p=.56$, and the test for the finance problem, $t(72)=-0.94, p=$ .35 , were nonsignificant. Therefore, choice of honorarium did not influence the dependent variables in the present study.

\section{A Priori}

Prior to conducting the a priori analyses, data were screened for missing values, outliers, and normality. Three cases were missing data on the just the financial problem strategy effectiveness score, one case was missing data on just the gossip problem strategy effectiveness score, and one case was missing both strategy effectiveness scores. These five missing cases were all older adult women; fortunately, the missing strategy effectiveness values consisted of only $2 \%$ of the scores and older adult women were slightly oversampled in the original existing data. Tabachnick and Fidell (2007) explain that datasets with less than five percent missing values are ideal. There were no missing values on the age or gender variables. In addition to the missing strategy effectiveness values, four outliers were excluded from the ANOVA. Outliers are extreme or atypical cases, which can be assessed by examining uncentered leverage statistics. The leverage statistic ranges from " 0 " (the outlier has no influence on the model) to " 1 " (the outlier has complete influence on the model) (Kline, 2005). In the present study, a leverage value above the cutoff value of $h=.06$ (based on the equation $h=2 \mathrm{p} / \mathrm{n}$, such that $\mathrm{p}$ is the number of variables and $\mathrm{n}$ is the sample size) indicated an outlier (Tanachnick \& Fidell, 2007). The four excluded cases had extreme leverage values $(h>.06)$, three of which were identified in box plots 
of the strategy effectiveness measures as significant outliers. Each outlier belonged to a different cell of the Age (younger adult, older adult) X Gender (men, women) design.

\section{Overall Strategy Effectiveness Ratings}

In order to test the first hypothesis that there would be a three-way interaction of age by gender by domain in overall strategy effectiveness scores, a 2 X 2 X 2 repeated-measures ANOVA was performed. Problem domain was the within-subjects variable. Age and gender were between-subjects variables. The dependent variables were the two overall strategy effectiveness scores. The three-way interaction, Age X Gender X Problem Domain, was not significant, $F(1,135)=0.00, p=.98, \eta_{p}{ }^{2}=.00$. Therefore, Hypothesis 1 was not directly supported.

The first-order interaction of Problem Domain X Age was also not significant, $F(1,135)=$ $0.05, p=.83, \eta_{p}{ }^{2}=.00$. Likewise, the main effect of gender was not significant, $F(1,135)=1.14$, $p=.29, \eta_{p}{ }^{2}=.01$.

Significant main effects of problem domain, $F(1,135)=136.31, p<.001, \eta_{p}{ }^{2}=.50$ and age, $F(1,135)=4.04, p<.05, \eta_{p}{ }^{2}=.03$ were qualified by significant first-order interactions. The first significant first-order interaction was Problem Domain X Gender, $F(1,135)=3.93, p<.05$, $\eta_{p}{ }^{2}=.03$. The second significant first-order interaction was Age X Gender, $F(1,135)=6.23, p<$ $.05, \eta_{p}{ }^{2}=.04$. In order to localize the interaction effects, two post-hoc tests were performed for each interaction. A Bonferroni-type correction was performed in order to reduce Type I error associated with multiple post-hoc tests; alpha was set at .0125 .

The first significant first-order interaction, Problem Domain X Gender, was examined by performing paired-samples $t$ tests on the two overall strategy effectiveness score variables separately for men and women. Significantly higher effectiveness scores were found for the finance problem than the gossip problem for both men and women, $p \mathrm{~s}<.001$. Inspection of mean differences in effectiveness scores between the two problem domains revealed a greater domain difference for men than women; the mean difference in effectiveness scores between the finance problem and gossip problem was 1.23 for men and 0.86 for women (see Figure 1).

In order to localize the effect of the significant Age X Gender interaction, data were collapsed across problem domain, the within-subjects variable. Therefore, multivariate simple effect tests were performed in order to capture both independent variables. A significant multivariate age difference was found for men, Wilks' $\Lambda=.94, F(2,135)=4.61, p<.013$, but 
not women, Wilks' $\Lambda=1.00, F(2,135)=0.12, p=.88$. Inspection of means revealed that older adult men had higher strategy effectiveness scores than did younger adult men (see Figure 2). Mediation of Age Difference in Strategy Effectiveness

To address the explanatory research question regarding whether self-efficacy beliefs about solving everyday problems or exposure to everyday problems mediate group differences in strategy effectiveness, path analyses were performed using AMOS 6.0. The following group differences in strategy effectiveness were found in the ANOVA: Gender X Domain interaction, Age X Gender interaction, main effects of age and domain. Prior to assessing mediation, Pearson correlations were performed in order to determine whether the potential mediators were candidates for mediation (i.e., were both significantly correlated with the predictor and the outcome) (see Table 3). Only exposure to the gossip problem met the criterion. It was significantly correlated with age and the overall strategy effectiveness ratings for the gossip problem, $p \mathrm{~s}<.05$. Therefore, because neither subscale of self-efficacy beliefs could be included in a mediation model, Hypothesis 2 (i.e., self-efficacy beliefs about one's ability to solve problems will at least partially mediate group differences in strategy effectiveness) was not supported.

Although repeated-measures ANOVA is robust to violations of normality, path analysis is sensitive to abnormality. Skew and kurtosis values and standard error were examined for the quantitative variables. Exposure to the gossip problem had little skew and kurtosis (value/SE < 1.96); the overall strategy effectiveness scores for the gossip problems, however, showed problematic skew (value/SE > 1.96). In order to reduce the negative skew, a square transformation was performed, such that the scale of the variable was altered (each value squared), while the relations among the values remained stable (Tabachnick \& Fidell, 2007).

In order to assess whether overidentified path models (one or more degrees of freedom) fit the data, several fit indexes were examined. The model chi square $\left(X^{2}\right)$ assesses the likelihood that the model's predicted correlations and covariances are equal to those that are observed (Kline, 2005). The smaller the $X^{2}$, the better the fit; ideally, the $X^{2}$ is nonsignificant (equivalent models), but chi square becomes inflated as sample size increases (Kline, 2005). Therefore, the root-mean-square error of approximation (RMSEA), a parsimony-adjusted population-based index of model fit to the population's covariance matrix, was also assessed. Smaller RMSEA values indicate better fit; an ideal RMSEA is less than .05 (Kline, 2005). The comparative fit 
index (CFI) assesses the improvement in fit of the observed model from a null model in which covariances among the observed variables are zero. Better CFI values are closest to 1.0, but greater than .90 is acceptable (Kline, 2005). The Akaike information criterion (AIC) index was also assessed. It is a parsimony-adjusted predictive fit index that is used to choose among competing nested models. Lower AIC values are representative of the preferred model (Kline, 2005). Models are also compared by examining the $X^{2}$ difference test, which compares the $X^{2}$ values between two nested models. The $X^{2}$ test indicates significant model fit improvement for the model with a lower $X^{2}$. This is accomplished through comparison of the observed difference in $X^{2}$ (and degrees of freedom) to the values in the $X^{2}$ distribution (Kline, 2005).

Path Model 1. Exposure to the gossip problem as a mediator of the age effect in overall strategy effectiveness for the gossip problem. In order to test Hypothesis 3 (i.e., exposure to problems will at least partially mediate group differences in strategy effectiveness), a path model was specified in which direct and indirect paths (through exposure to the gossip problem) were drawn from the exogenous predictor variable (i.e., age) to the outcome variable (i.e., overall strategy effectiveness scores). First, the indirect paths in the model were constrained to zero, so that the direct effect of age on strategy effectiveness could be assessed. The direct path was significant, $p=.05$. This model had poor fit to the data, $\mathrm{CFI}=0.00, \mathrm{RMSEA}=0.35, \mathrm{AIC}=$ $52.85, X^{2}(2, N=148)=38.85, p<.001$. Then, the indirect paths as well as the direct path were allowed to be estimated (See Table 4 for path coefficients). This saturated mediation model revealed that the direct path of age on strategy effectiveness was no longer significant, $p=.56$, but the indirect paths from age to exposure and exposure to strategy effectiveness were significant, $p \mathrm{~s}<.05$. The final model removed the nonsignificant direct effect from the analysis. This model fit the data very well, $\mathrm{CFI}=1.00, \mathrm{RMSEA}=0.0, \mathrm{AIC}=16.09, X^{2}(1, N=148)=$ $0.09, \mathrm{~ns}$, and was a significant improvement compared to the direct effect model, $X^{2}$ difference $(1)=38.76, p<.001$. The age effect in overall strategy effectiveness for the gossip problem was mediated through exposure to the gossip problem. Being a younger adult was associated with having a greater amount of exposure to the gossip problem; greater exposure was related to lower effectiveness scores on the gossip problem. See Figure 3 for the path model and standardized path estimates that confirmed Hypothesis 3. 


\section{Exploratory}

The mediation of the age differences in overall strategy effectiveness for the gossip problem through exposure to the gossip problem revealed that greater exposure was associated with poor strategy effectiveness. Given the three dimensions of strategy effectiveness examined in the present study, a theoretical cause for younger adults and men have poorer effectiveness scores and experiencing the gossip problem more often than older adults or women is that they use strategies that do not solve the problem and/or are low in preventing or minimizing future occurrences of the problem. Pearson correlations revealed that age, the degree to which a strategy prevents or minimizes future occurrence of the problem, and the degree to which a strategy solves the problem were significantly correlated with exposure to the gossip problem, $p \mathrm{~s}$ $<.05$. Therefore, Path Model 1 was re-specified in order to examine the two dimensions of effectiveness mentioned above.

Path Model 2. Exposure to the gossip problem as a mediator of the age effect in the degree to which strategies solve the gossip problem. Like Path Model 1, the direct effect model (indirect effects constrained to zero) had poor fit to the data, $(\mathrm{CFI})=0.00$, root-mean-square error of approximation $($ RMSEA $)=0.35$, Akaike information criterion $(\mathrm{AIC})=51.95, X^{2}(2, N=$ $148)=37.95, p<.001$. When the indirect paths as well as the direct path were allowed to be estimated, the saturated mediation model revealed that the direct path of age on strategy effectiveness was no longer significant, $p=.63$, but the indirect paths from age to exposure and exposure to strategy effectiveness were significant, $p \mathrm{~s}<.05$. The final model removed the nonsignificant direct effect from the analysis. This model fit the data very well, CFI $=1.00$, $\mathrm{RMSEA}=0.0, \mathrm{AIC}=16.24, X^{2}(1, N=148)=0.24, \mathrm{~ns}$, and was a significant improvement than the direct effect model, $X^{2}$ difference $(1)=37.71, p<.001$. Being a younger adult was associated with having a greater amount of exposure to the gossip problem; greater exposure was related to lower scores on the solve the problem dimension of effectiveness.

Path Model 3. Exposure to the gossip problem as a mediator of the age effect in the degree to which strategies prevent or minimize future occurrence of the gossip problem. Like Path Models 1 and 2, the direct effect model (indirect effects constrained to zero) had poor fit to the data, $(\mathrm{CFI})=0.00$, root-mean-square error of approximation $(\mathrm{RMSEA})=0.36$, Akaike information criterion $($ AIC $)=53.40, X^{2}(2, N=148)=39.40, p<.001$. When the indirect paths as well as the direct path were allowed to be estimated, the saturated mediation model revealed that 
the direct path of age on strategy effectiveness was no longer significant, $p=.58$, but the indirect paths from age to exposure and exposure to strategy effectiveness were significant, $p \mathrm{~s}<.05$. The final model removed the nonsignificant direct effect from the analysis. This model fit the data very well, $\mathrm{CFI}=1.00, \mathrm{RMSEA}=0.0, \mathrm{AIC}=16.30, X^{2}(1, N=148)=0.30, \mathrm{~ns}$, and was a significant improvement than the direct effect model, $X^{2}$ difference $(1)=39.10, p<.001$. Being a younger adult was associated with having a greater amount of experience with the gossip problem; greater experience was related to lower scores on the degree to which the strategy prevents/minimizes future occurrence of the problem. 


\section{Discussion}

The goals of the present investigation into everyday problem-solving were to 1) uncover systematic differences among adults' strategy effectiveness due to age, gender, and problem domain, 2) examine explanatory variables for group differences uncovered during examination of the first goal (i.e., self-efficacy beliefs about solving everyday problems, exposure to the problems), and 3) improve upon prior methods of determining strategy effectiveness. The present investigation was novel in that person and contextual variables typically examined within the everyday problem solving literature were applied to the important concept of strategy effectiveness. Strategy effectiveness has been understudied in the everyday problem-solving literature. On average, adults of both age groups and genders tended to be fairly effective problem solvers (i.e., overall ratings between " 4 " and "6" on a sale of " 1 " (least effective) to "7" (most effective). However, systematic differences did occur among groups, both in terms of overall problem-solving effectiveness and the predictors of differences between groups.

\section{Problem Domain by Gender Interaction}

In the present study, problem domain interacted with gender, such that domain differences in strategy effectiveness were more pronounced for men than for women. Regardless of gender, individuals were more effective problem solvers for the instrumental (finance) problem than the interpersonal (gossip) problem. These results were consistent with prior work that has found more effective strategy choices for solving problems of instrumental domains than interpersonal domains (Blanchard-Fields et al., 2007). Domain differences were more pronounced for men than for women. Prior research has suggested that women may have more variability in strategy use than men when solving interpersonal problems (Watson \& BlanchardFields et al., 1998), which contain socio-emotional content (Allaire \& Marsiske, 2002). Women may be more likely to incorporate emotion-regulation strategies for interpersonal problems (Blanchard-Fields et al., 2004; Watson and Blanchard-Fields, 1998). However, men and women in the present study had approximately equal variability in strategy use in both domains. Therefore, the greater domain difference for men than for women is likely not due to strategy variability. Further research may explore other factors that may moderate gender by domain differences. The greater domain difference in effectiveness scores was not the only effect in which men showed more-pronounced effects. A similar phenomenon occurred for the Age X Gender interaction. 


\section{Age by Gender Interaction}

As expected, the results of the present study showed significant age differences for men, but not women. Older adult men outperformed younger adult men in terms of strategy effectiveness. These findings are consistent with previous research. Blanchard-Fields et al. (2007) found that older adults were more effective than younger adults in their strategy choice for interpersonal problems. In addition to explaining the age and gender effects due to variability of strategy use, one must consider the quality of strategies chosen. For example, low variability may increase strategy effectiveness scores if the strategies that were selected tended to be rated as better strategies.

\section{Exposure as a Mediator of Interpersonal Problem Solving}

What was it about the gossip problem that the significant age and gender differences were found for that problem, but not the finance problem? A strength of the present study is that explanatory variables were hypothesized (i.e., self-efficacy beliefs and exposure to everyday problems would mediate group differences in effectiveness). Although self-efficacy beliefs were not candidates for mediation, exposure to the gossip problem was a significant mediator of the age effect in strategy effectiveness. Younger adults had greater amounts of exposure to the gossip problem than did older adults. This finding was consistent with Blanchard-Fields et al. (1997), in which all age groups were more familiar than older adults with the interpersonal (friend) domain problem. However, in the present study, the greater exposure was associated to lower effectiveness scores on the gossip problem.

The present tense wording of current exposure to everyday problems in the present investigation suggested that the underlying reason for having greater exposure to everyday problems may have been related to individuals' ability to solve their problems. The exposure items measured how often people currently encountered those problems. Younger adults may have been exposed to more current gossip situations than older adults, but older adults most likely had greater cumulative exposure to gossip over the course of their life spans. Therefore, according to Sansone and Berg's (1993) model, older adults had more opportunities for adaptation in problem solving. Perhaps the older adults chose strategies that they knew would be effective. Younger adults may have been exposed to more gossip problems because their strategies for dealing with those problems were less effective. Alternately, it is possible that 
younger adults had not chosen friends wisely; they may have been attracted to the type of friends that gossip.

What was it about strategy effectiveness that accounted for a decrease in exposure to the gossip problem for older adults? It was the degree to which the strategy solved the problem and prevented or minimized future occurrences of the problem. Older adults chose strategies that were rated more likely to solve the problem and more likely to prevent or minimize future occurrences of the problem than those selected by younger adults. The components of effectiveness were explored in order to understand what dimensions of effectiveness were important for understanding group differences and the role of exposure in problem solving. This study found strategy dimensions to be an important component of examining age differences and adaptation to problematic situations over the life span.

\section{Limitations and Future Directions}

The present research contained several limitations that must be acknowledged. First, all measures were completed within one session. Therefore, confidence in the mediation models must be held cautiously. Future research should examine the problem-solving process using more micro-genetic designs. Other researchers should assess mediators of variables commonly examined, such as age and gender. Often, these predictor variables may serve as proxies for other variables that have a more direct influence on problem-solving outcome. A second limitation is that the present study was cross-sectional. Age differences found in the present study could be a developmental phenomenon or a history-graded effect. Different cohorts of participants and age of participants was confounded. Therefore, future research should assess longitudinal everyday problem-solving effectiveness.

Third, only one problem was assessed for each domain. Therefore, conclusions based upon the results were limited to those two problems rather than more general interpersonal or instrumental domains. Due to the contextual nature of everyday problem solving, future research should examine the concept of effectiveness across multiple problems of various domains. Fourth, effectiveness ratings provided by experts were biased slightly in favor of the instrumental problem. Therefore, it was unclear how much of the mean differences due to domain effects were due to differential strategy choice and/or differential strategy ratings. It is likely that adults are generally effective problem solvers across domains. If so, then the differences due to domain in the present study were probably related to the lower variability of strategies within the 
instrumental problem and the bias toward higher effectiveness ratings for the instrumental problem strategies. Alternately, it is possible that there were no biases; individuals may just select more effective strategies due to the nature of instrumental problem solving (or at least the finance problem). Future research should tease apart the differences between domains when ratings are used to replace strategy codes.

Fifth, there were more strategies rated for the gossip problem than were rated for the finance problem. However, this matches previous research findings that more variability occurs in interpersonal problem solving than in instrumental problem solving. Sixth, problem definitions were not examined in the present study. In order to fully understand strategy effectiveness and the process by which effective strategies are enacted, future research should examine the correspondence of person and context variables on problem definitions and problem definitions on strategy effectiveness. Finally, the effect sizes of these different variables should also be considered in interpretation of the current results and in preparation for further research. The main effect for domain was a large effect, but when qualified by the significant interactions, the interaction effect sizes were relatively smaller. The small effect sizes for age differences in problem solving found in the current study is consistent with other research on effectiveness (Blanchard-Fields et al., 2007).

This research was the first to examine expert effectiveness ratings of strategies generated and chosen as most-effective by older and younger adult participants during everyday problemsolving tasks. The current study improved upon ecological validity of examining strategy effectiveness by not forcing participants to choose from a prefabricated strategy list. Rather, participants were free to generate strategies that matched their problem definitions for each situation. However, it must be noted that real-world factors that influence whether a strategy is employed were not examined in the current study. Hypothetical vignette research, like the present study, should be supplemented with everyday problem simulations in the lab and/or in the field.

Third, the current study looked to previous attempts at assessing strategy effectiveness or quality using independent raters as examples and sources of improvement suggestions. Then, these methodological improvements were applied to interpersonal and instrumental everyday problem solving. The expert ratings in the current study reflected a modern sample of professionals who had expertise in helping younger and older adults solve everyday problems. 
These independent expert raters were not biased to the aims of the present research. The expert raters were men and women of all ages and levels of expertise and had very high reliability. However, there is always need for further improvement in sample recruitment, especially in obtaining diverse samples.

\section{Conclusions}

Strategy effectiveness is a useful and important dependent variable in everyday problemsolving research, but has been understudied. Research is beginning to improve methods of examining the quality of individuals' strategies. The present research found similar age, gender, and domain effects as previous literature, suggesting that older adults have an advantage in everyday problem solving outcomes and may be better-adapted problem solvers, especially when compared to younger adult men. Mediating factors, like problem exposure account for part of the variance in age by gender influences on strategy effectiveness. Furthermore, younger adults may be less adapted than older adults in that their problem-solving strategies are less likely to prevent or minimize future problem occurrences. Older adults tend to choose safer strategies than younger adults; instrumental problem strategies tend to be rated as more effective. 


\section{References}

Allaire, J. C., \& Marsiske, M. (1999). Everyday cognition: Age and intellectual ability correlates. Psychology and Aging, 14, 627-644.

Allaire, J. C., \& Marsiske, M. (2002). Well- and ill-defined measures of everyday cognition: Relationship to older adults' intellectual ability and functional status. Psychology and Aging, 17, 101-115.

Artistico, D., Cervone, D., \& Pezzuti, L. (2003). Perceived self-efficacy and everyday problemsolving among young and older adults. Psychology and Aging, 18, 68-79.

Baron, R. M., \& Kenny, D. A. (1986). The moderator-mediator variable distinction in social psychological research: Conceptual, strategic, and statistical considerations. Journal of Personality and Social Research, 51, 1173-1182.

Berg, C. A. (1989). Knowledge of strategies for dealing with everyday problems from childhood through adolescence. Developmental Psychology, 25, 607-618.

Berg, C. A., Klaczynski, P. A., Calderone, K. S, \& Strough, J. (1994). Adult age differences in cognitive strategies: Adaptive or deficient? In J. Sinnott (Ed.), Interdisciplinary handbook of adult lifespan learning (pp. 371-388). Westport, CT: Greenwood Press.

Berg, C. A., Meegan, S. P., \& Klacsynski, P. (1999). Age and experiential differences in strategy generation and information requests for solving everyday problems. International Journal of Behavioral Development, 23, 615-639.

Berg, C. A., Strough, J., Calderone, K. S., Meegan, S. P., \& Sansone, C. (1997). Planning to prevent everyday problems from occurring. In S. C. Friedman \& E. K. Kofsky (Eds.), The developmental psychology of planning: Why, how, and when do we plan? (pp. 209236). Mahwah, NJ: Erlbaum.

Berg, C. A., Strough, J., Calderone, K. S., Sansone, C., \& Weir, C. (1998). The role of problem definitions in understanding age and context effects on strategies for solving everyday problems. Psychology and Aging, 13, 29-44.

Blanchard-Fields, F., \& Camp, C. J. (1990). Affect, individual differences, and real world problem solving across the adult life span. In T. Hess (Ed.), Aging and Cognition: Knowledge organization and utilization (pp. 461-497). Amsterdam: North Holland. 
Blanchard-Fields, F., Chen, Y., \& Norris, L. (1997). Everyday problem-solving across the adult life span: Influence of domain specificity and cognitive appraisal. Psychology and Aging, 12, 684-693.

Blanchard-Fields, F., Jahnke, H. C., \& Camp, C. (1995). Age differences in problem-solving style: The role of emotional salience. Psychology and Aging, 10, 173-180.

Blanchard-Fields, F., Mienaltowski, A., \& Seay, R. B. (2007). Age differences in everyday problem-solving effectiveness: Older adults select more effective strategies for interpersonal problems. Journal of Gerontology: Psychological Sciences, 62B, P61-P64.

Blanchard-Fields, F., Stein, R., \& Watson, T. L. (2004). Age differences in emotion-regulation strategies in handling everyday problems. Journal of Gerontology: Psychological Sciences, 59B, P261-P269.

Cohen, J., \& Cohen, P. (1983). Applied multiple regression/correlation analysis for the behavioral sciences ( $2^{\text {nd }}$ ed.).Hillsdale, NJ: Lawrence Erlbaum Associates.

Cornelius, S.W., \& Caspi, A. (1987). Everyday problem solving in adulthood and old age. Psychology and Aging, 2, 144-153.

Crick, N. R., \& Dodge, K. A. (1994). A review and reformulation of social informationprocessing mechanisms in children's social adjustment. Psychological Bulletin, 115, 74101.

Denney, N. W. (1989). Everyday problem-solving: Methodological issues, research findings and a model. In L. W. Poon, D. C. Rubin, and B. A. Wilson (Eds.). Everyday cognition in adulthood and later life (pp. 330-351). New York: Cambridge University Press.

Denney, N. W., \& Pearce, K. A. (1989). A developmental study of practical problem solving in adults. Psychology and Aging, 4, 438-442.

D’Zurilla, T. J., Nezu, A. M., \& Maydeu-Olivares, A. (2004). Social problem solving: Theory and assessment. In E. C. Chang, T. J. D’Zurilla, \& L. J. Sanna (Eds.), Social problem solving (pp. 11-27). Washington, DC: American Psychological Association.

Erdfelder, E., Faul, F., \& Buchner, A. (1996). GPower: A general power analysis program. Behavior Research Methods, Instruments, \& Computers, 28, 1-11.

Galambos, N. L., MacDonald, S. W. S., Naphtali, C., Cohen, A.-L., \& de Frias, C. M. (2005). Cognitive performance differentiates selected aspects of psychosocial maturity in adolescence. Developmental Neuropsychology, 28, 473-492. 
Griffin, D., \& Gonzalez, R. (1995). Correlational analysis of dyad-level data in the exchangeable case. Psychological Bulletin, 118, 430-439.

Howell, D. C. (2002). Statistical methods for psychology (5 $5^{\text {th }}$ ed.). Pacific grove, PA: Duxbury.

Kenny, D. A., \& Judd, C. M. (1996). A general procedure for the estimation of interdependence. Psychological Bulletin, 119, 138-148.

Kline, R. B. (2005). Principles and practices of structural equation modeling (2 $2^{\text {nd }}$ ed.). New York: Guilford Press.

Lawton, M. P., Moss, M. S., Fulcomer, M., \& Kleban, M. H. (1982). A research and service oriented multilevel assessment instrument. Journal of Gerontology, 37, 91-99.

Lewin, K. (1951). Field theory in social science: Selected theoretical papers (D. Cartwright, Ed.). New York: Harper \& Row.

Marsiske, M., \& Margrett, J. A. (2006). Everyday problem solving and decision making. In J. E. Birren \& W. K. Schaie (Eds.), Handbook of the psychology of aging (pp. 315-342). Boston: Academic Press.

Marsiske, M., \& Willis, S. L. (1995). Dimensionality of everyday problem solving in older adults. Psychology \& Aging, 10, 269-283.

Patrick, J. H., \& Strough, J. (2004). Everyday problem solving: Experience, strategies, and behavioral intentions. Journal of Adult Development, 11, 9-18.

Polanyi, M. (1967). The tacit dimension. New York: Anchor Books.

Salthouse, T. A. (1984). The skill of typing. Scientific American, 250, 128-135.

Sansone, C., \& Berg, C. A. (1993). Adapting to the environment across the life span: Different process or different inputs? International Journal of Behavioral Development, 16, 215241.

Smith, J., Staudinger, U. M., \& Baltes, P. B. (1994). Occupational settings facilitating wisdomrelated knowledge: The sample case of clinical psychologists. Journal of Consulting and Clinical Psychology, 62, 989-999.

Strough, J. (2004). Collaborative everyday problem solving: Gain or Loss? R-03 grant funded by the National Institute of Health.

Strough, J., Berg, C. A., \& Sansone, C. (1996). Goals for solving everyday problems across the life span: Age and gender differences in the salience of interpersonal concerns. Developmental Psychology, 32, 1106-1115. 
Strough, J., Cheng, S., \& Swenson, L. M. (2002). Preferences for collaborative and individual everyday problem solving in alter adulthood. International Journal of Behavior Development, 26, 26-35.

Strough, J., McFall, J. P., Flinn, J. A., \& Schuller, K. L. Collaborative everyday problem solving among same-gender friends in early and later adulthood. Manuscript submitted for publication.

Strough, J., Patrick, J. H., \& Swenson, L. M. (2003). Strategies for solving everyday problems faced by grandparents: The role of experience. In B. Hayslip, Jr., \& J. H. Patrick (Eds.). Working with custodial grandparents (pp. 257-275). New York: Springer Publishing Co.

Swenson, L.M. (2003). Adolescent relationship quality and delinquency: Associations with social and cognitive problem solving performance. Unpublished doctoral dissertation. West Virginia University, Morgantown, WV.

Tabachnick, B. G., \& Fidell, L. S. (2007). Using multivariate statistics $\left(5^{\text {th }}\right.$ ed.). Boston: Pearson.

Thornton, W. J. L., \& Dumke, H. A. (2005). Age differences in everyday problem-solving and decision-making effectiveness: A meta-analytic review. Psychology and Aging, 20, 8599.

Watson, T. L., \& Blanchard-Fields, F. (1998). Thinking with your head and with your heart: Age differences in everyday problem-solving strategy preferences. Aging, Neuropsychology, and Cognition, 5, 225-540.

Willis, S. L., \& Marsiske, M. (1994). Psychometric characteristics of the Everyday Problems Test. Unpublished manuscript, University Park, Pennsylvania State University. 
Table 1

Older and Younger Adults' Strategies for Solving the Gossip Problem: Average Expert Ratings and Percentage Selecting by Age Group.

\begin{tabular}{|c|c|c|c|}
\hline \multirow[t]{2}{*}{ Strategy } & \multirow[t]{2}{*}{ Rating } & \multicolumn{2}{|c|}{ Frequency $(\%)$} \\
\hline & & Younger & Older \\
\hline Don't allow yourself to add to the gossip. & 4.52 & 2.7 & 5.4 \\
\hline Speak up on behalf of your friend. & 4.52 & 41.9 & 33.8 \\
\hline Engage the people in the group in a discussion about the situation. & 4.48 & 0.0 & 9.5 \\
\hline Tell them to stop gossiping about your friend. & 4.38 & 14.9 & 14.9 \\
\hline Pray about the situation. & 4.33 & 0.0 & 1.4 \\
\hline Leave the group. & 4.10 & 4.1 & 9.5 \\
\hline Explain to them why they shouldn't gossip. & 3.95 & 9.5 & 4.1 \\
\hline Change the subject. & 3.62 & 2.7 & 8.1 \\
\hline Forget what the people in the group said and move on. & 3.48 & 1.4 & 0.0 \\
\hline Consider the source of the information. & 3.33 & 1.4 & 4.1 \\
\hline Just sit there to make them feel weird. & 3.00 & 1.4 & 0.0 \\
\hline Ignore what the people in the group are saying. & 2.86 & 4.1 & 2.7 \\
\hline Hope the talk will stop. & 2.76 & 1.4 & 0.0 \\
\hline Just sit and listen. & 2.71 & 4.1 & 1.4 \\
\hline Listen to what they're talking about. & 2.62 & 2.7 & 0.0 \\
\hline Do nothing. & 2.38 & 5.4 & 2.7 \\
\hline Tell your friend about the rumors. & 2.19 & 2.7 & 0.0 \\
\hline (Missing) & & 0.0 & 2.7 \\
\hline
\end{tabular}


Table 2

Older and Younger Adults' Strategies for Solving the Finance Problem: Average Expert Ratings and Percentage Selecting by Age Group.

\begin{tabular}{lrrr}
\hline \multicolumn{1}{c}{ Strategy } & Rating & \multicolumn{2}{c}{ Frequency (\%) } \\
& & Younger & Older \\
\hline Figure out ways to save money. & 6.00 & 8.1 & 12.2 \\
Try to cut down on spending so you can pay the bills. & 6.00 & 13.5 & 21.6 \\
Do things that will increase your income. & 5.81 & 28.4 & 9.5 \\
Make the best out of money you do have. & 5.57 & 2.7 & 8.1 \\
Reconsider what you spend on. & 5.29 & 1.4 & 0.0 \\
Discuss the situation with other members of the household. & 4.71 & 0.0 & 2.7 \\
Get help to pay bills from family, friends, creditors, other resources. & 4.19 & 45.9 & 37.8 \\
Go bankrupt. & 2.24 & 0.0 & 1.4 \\
Don't worry about the bills. & 1.38 & 0.0 & 1.4 \\
(Missing) & & 0.0 & 5.4 \\
\hline
\end{tabular}


Table 3

Correlations Between the Major Variables.

\begin{tabular}{|c|c|c|c|c|c|c|c|c|}
\hline Variable & 1 & 2 & 3 & 4 & 5 & 6 & 7 & 8 \\
\hline 1. Age & - & & & & & & & \\
\hline 2. Gender & $.19^{*}$ & - & & & & & & \\
\hline 3. Age X Gender & $.22^{* *}$ & -.04 & - & & & & & \\
\hline 4. Gossip problem exposure & $-.45^{* *}$ & $-.23^{* *}$ & .05 & - & & & & \\
\hline 5. Finance problem exposure & -.09 & -.01 & -.02 & $.16^{\wedge}$ & - & & & \\
\hline 6. Self-efficacy change in ability & $-.67^{* *}$ & -.06 & $-.19^{*}$ & $.25^{* *}$ & .09 & - & & \\
\hline 7. Self-efficacy compared to others & .09 & .05 & $.26 * *$ & .06 & -.05 & .16 & - & \\
\hline 8. Gossip problem strategy effectiveness & $.16^{\wedge}$ & .12 & -.11 & $-.23^{* *}$ & -.08 & -.03 & .11 & - \\
\hline 9. Finance problem strategy effectiveness & -.02 & -.10 & -.08 & .04 & -.04 & -.06 & -.06 & .07 \\
\hline
\end{tabular}


Table 4

Mediation of the Age Difference in Overall Strategy Effectiveness for Solving the Gossip Problem through Exposure with the Gossip Problem: Standardized and Unstandardized Coefficients and Standard Error (S.E.).

\begin{tabular}{lccc}
\multicolumn{1}{c}{ Path } & \multicolumn{2}{c}{ Coefficient } & S.E. \\
& Standardized & Unstandardized \\
\hline Direct & & & \\
Age to strategy effectiveness & .03 & 0.35 & 1.19 \\
Age to exposure & -.45 & -1.68 & 0.27 \\
Exposure to strategy effectiveness & -.21 & -0.74 & 0.32 \\
Indirect & & & 1.24 \\
Age to strategy effectiveness through exposure & .10 & & \\
\hline
\end{tabular}




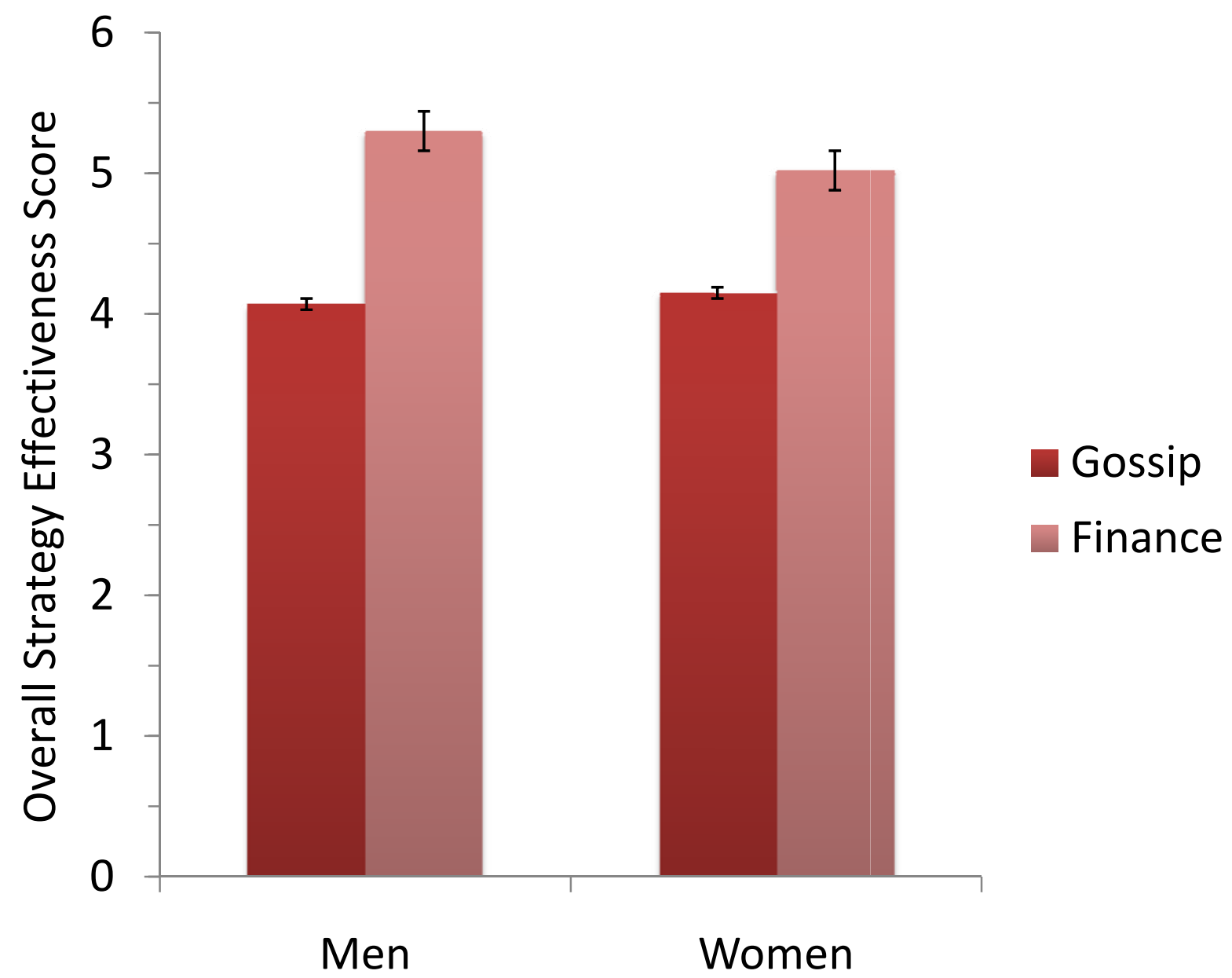

Figure 1: Overall Strategy Effectiveness Scores: Problem Domain X Gender 


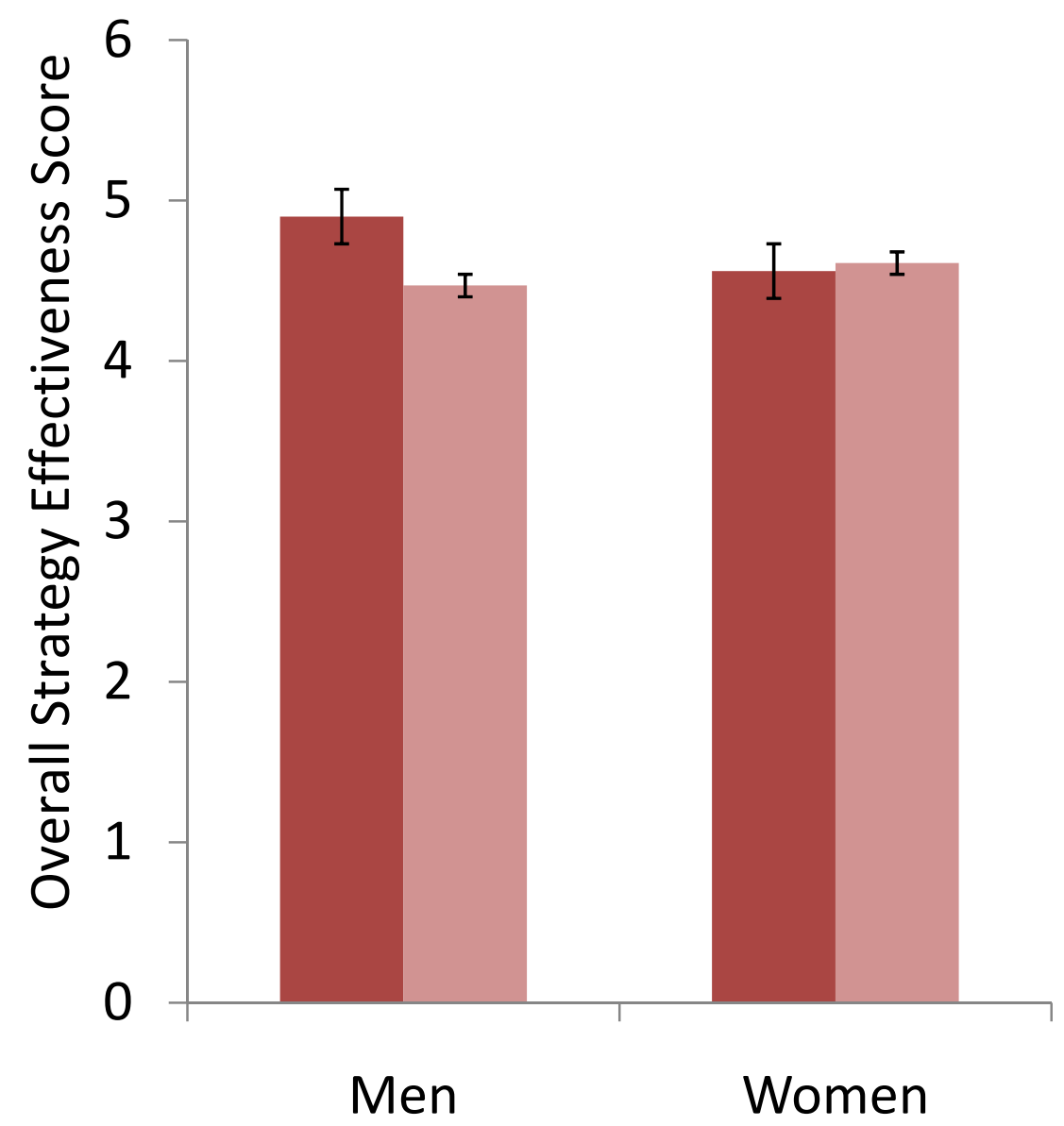

- Older adults - Younger adults

Figure 2: Overall Strategy Effectiveness Scores: Age X Gender 


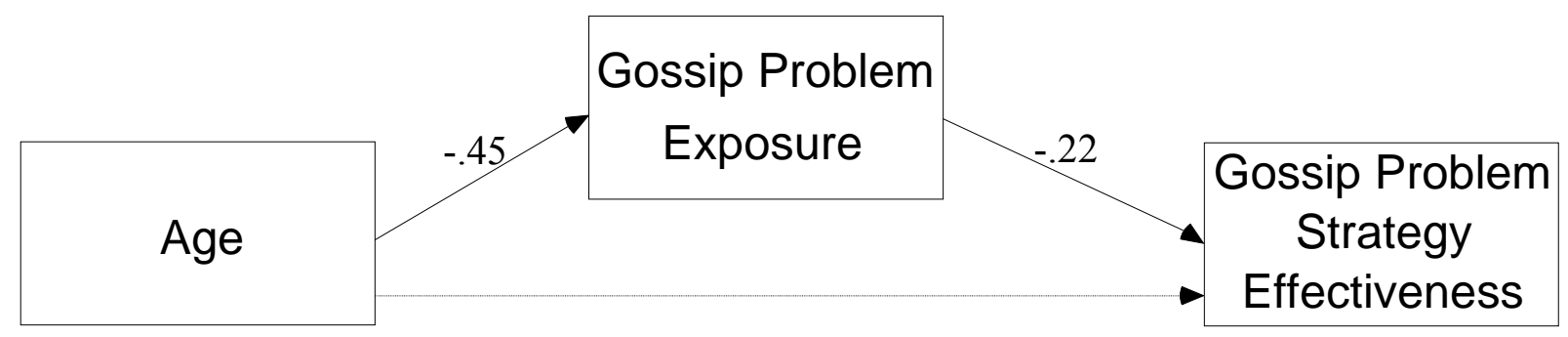

Figure 3: Path Model 1: Exposure to the Gossip Problem as a Mediator of Age Differences in Strategy Effectiveness Scores for the Gossip Problem 


\section{Appendix A}

\section{Demographics Questionnaire}

- Sex: $\square$ Male $\square$ Female (check one)

- Age: in years

- Date of Birth: (Month/Day/Year)

- Race (check one): $\square$ African American

$\square$ Asian

$\square$ Caucasian

$\square$ Hispanic

$\square$ Biracial (Specify):

$\square$ Other (Specify):

- Number of years of education:

in years

(Examples: High school degree $=12$ years; two years of college $=14$ years; four years of college $=16$ years)

- Highest Degree Earned:

(Examples: High school diploma, associates, bachelors, masters, doctoral)

- What is your marital status?

(Check one \& please specify number of years).

Married for yrs. \& _ mo.

Not married, but living together for yrs. \& _ mo. Widowed, married for Divorced, married for yrs \& widowed for yrs.

Never married yrs. \& and divorced for yrs.

Other (specify:

Estimation of the yearly income you (and members of your household if you share expenses) received last year from all sources. Include wages, social security, pensions, annuities, interest, etc:

$\begin{array}{ll}\text { less than } 10,000 & 50,000-59,000 \\ 10,000-19,900 & -60,000-69,000 \\ 20,000-29,000 & \text { 70,000 or more } \\ 30,000-39,000 & \text { I do not know/don't wish to answer } \\ 40,000-49,000 & \end{array}$


Do you currently live: (Check one)

$\square$ Alone
$\square$ With a spouse
$\square$ With a significant other (boyfriend/girlfriend)
$\square$ With a friend who is not related to me
$\square$ With relatives (specify relationship:
$\square$ With others (specify relationship_

What kind of work have you done most of your life? (specify):

For what kind of business, company or agency is that? (specify):

What is your current work status? Are you:

$\square$ Employed full time
$\square$ Employed part time
$\square$ Retired
$\square$ Unemployed
$\square$ Homemaker
$\square$ Other (specify

What kind of work does/did your mother do?

What kind of work does/did your father do?

What kind of work does/did your spouse do?

- Number of siblings: (living and deceased)

- Number of children: (living and deceased)

- What city/town and state are you a permanent resident of? city/town state:

For the items below, please place a check mark next to the item that best describes you.

How would you rate your overall health at the present time?

$\square$ Excellent

$\square$ Good

$\square$ Fair

$\square$ Poor 
Is your health now better, about the same, or not as good as it was 3 years ago?

$\square$ Better
$\square$ Same
$\square$ Not as good

Do your health problems stand in the way of your doing the things you want to do?

$\square$ Not at all
$\square$ A little
$\square$ A great deal

Compared with most other people your age, would you say your health is:

$\square$ Better,

$\square$ The Same

$\square$ Not as good?

Compared with most people your age, would you say your memory is:

$\square$ Better,

$\square$ The Same

$\square$ Not as good? 


\section{Appendix B}

\section{Questions to Examine Expertise}

1. Select the choice that matches your current occupation:
a. social work
e. psychology
b. medicine/psychiatry
f. counseling
c. nursing
g. nursing home administration
d. education
h. other, specify:

2. How many consecutive years have you worked in that occupation?

3. How many total years have you worked in that occupation?

4a. Which of the following groups of people do you help problem solve (check all that apply)?
a. Older adults $(60+$ years old $)$
b. Middle-aged adults (30-59 years old)
c. Younger adults (18-29 years old)
d. Adolescents (13-17 years old)
e. Children (0-12 years)
f. Not applicable

4b. What do you help them do?

5. To what degree to you consider yourself an expert at solving interpersonal problems (those that involve other people, like friends, family, coworkers). Use a scale from "Definitely NOT an expert" (1) to "May or may not be an expert" (3) to "Definitely an expert" (5).

6. On the same scale, to what degree do you consider yourself to be an expert on problems relevant only to the individual, like fixing equipment problems? 


\section{Appendix C}

Self-Efficacy Scale: Perceived Ability Compared with Others of the Same Age

For the items below, please place a check mark next to the item that best describes you.

Compared with most people your age, would you say your ability to solve everyday problems is

$\square$ Better,

$\square$ The Same

$\square$ Not as good?

Compared with most people your age, would you say your ability to solve interpersonal conflicts is:

Better,

The Same

Not as good?

Compared with most people your age, would you say your ability to solve problems dealing with housework and managing a household is:

$\square$ Better,

The Same

Not as good?

Compared with most people your age, would you say your ability to make everyday judgments and decisions is:

Better,

The Same

Not as good?

Compared with most people your age, would you say your ability to solve everyday problems dealing with your health is:

$\square$ Better,

$\square$ The Same

Not as good?

Compared with most people your age, would you say your ability to solve everyday problems dealing with your memory is:

Better,

The Same

Not as good?

Compared with most people your age, would you say your ability to solve everyday problems dealing with preparing meals is: 


\section{$\square$ Better, The Same \\ $\square$ Not as good?}

Compared with most people your age, would you say your ability to solve everyday problems dealing with medication is:

$\square$ Better,

$\square$ The Same

$\square$ Not as good?

Compared with most people your age, would you say your ability to solve everyday problems dealing with finances is:

$\square$ Better,

The Same

$\square$ Not as good? 


\section{Appendix D}

Self-Efficacy Scale: Change in Perceived Ability Over the Past Several Years

Please answer the following items about how you view your ability to deal with everyday problems. Circle one alternative for each question.

\section{As I have gotten older, my ability to:}

a. solve everyday problems has:

b. solve interpersonal conflicts has:

c. solve everyday problems with housework and managing a Improved household has:

d. make everyday decisions and judgments everyday problems has:

e. solve everyday problems with my health has:

f. solve everyday problems dealing with my memory has:

g. solve everyday problems dealing with preparing meals has:

h. solve everyday problems dealing with medications has:

i. solve everyday problems dealing with finances has:

$$
\text { This ability }
$$

has

Improved

Improved

Improved

Improved

Improved

Improved

Improved

Improved

Improved
This ability has Not ability has

Changed Declined

Not Declined
Changed

Not Declined
Changed

Not Declined Changed

Not Declined
Changed

$$
\text { Not }
$$

Declined Changed

$$
\text { Not }
$$

Declined Changed

Not Declined
Changed

$$
\text { Not }
$$

Declined Changed

Not Changed
Declined 


\section{Appendix E}

\section{Strough et al. (2007) Strategy Coding Scheme}

\section{Action and cognition (PF)}

Behavioral Inhibition. Decreasing or "cutting back" on some behavior to solve the problem.

Deliberation. One regulates own thoughts: includes thinking about the situation, planning action, finding more information about the problem.

Self-action. Self-initiated action to alter one's own behavior in order to solve or deal with the demands presented by the problem.

Interpersonal constructive (PF)

Discussion. One attempts to non-confrontationally engage in others who are directly involved in the problem, considering both points of view, or gathering more information about the problem from others via discussion.

Seek instrumental support. Seeking assistance from others to assist one in solving the problem, which may include giving control over the problem to others and making others responsible for solving the problem.

Self-assertion. Actions taken to further one's own self-interests, confronting others, and asserting one's own will.

Interpersonal destructive $(P F)$

Aggression. Aggressive actions directed toward others that may or may not involve physical harm, but are socially inappropriate behavior.

Verbal aggression. Abusive or aggressive talk used in an attempt to solve the problem and to hurt the other person.

Proactive (EF)

Accepting influence. One attempts to conform to the situation by altering own behavior to conform or compromise with another person's point of view.

Emotion regulation. One thinks about the emotional state or feelings, may include action related to catharsis or "blowing off steam." 
Passive (EF)

Doing nothing. One inhibits action/behavior to delay or avoid dealing with the problem. Ignoring the problem. One avoids thinking about the situation.

Leaving the situation. The problem solver avoids further involvement in the problem by leaving the situation or avoiding it in the future.

Passive acceptance. One accepts the situation as a whole and puts it in the past.

Other

Crimes. Taking or damaging another person's property or engaging in illegal acts.

Other. Strategies that do not fit into the above scheme. 


\section{Appendix F}

Problem Vignettes and Representative Strategies to be Rated by Experts

Interpersonal Problem Vignette

You are with a group of people who begin gossiping about one of your friends. What do you do?

\section{Representative Strategies}

Consider the source of the information.

Ignore what the people in the group are saying.

Hope the talk will stop.

Forget what the people in the group said and move on.

Pray about the situation.

Change the subject.

Leave the group.

Don't allow yourself to add to the gossip.

Listen to what they're talking about.

Engage the people in the group in a discussion about the situation.

Tell your friend about the rumors.

Tell them to stop gossiping about your friend.

Explain to them why they shouldn't gossip.

Just sit there to make them feel weird.

Do nothing.

Speak up on behalf of your friend.

Just sit and listen.

\section{Individual Problem Vignette}

You have a limited income. You don't have enough money to pay your bills. What do you do?

\section{Representative Strategies}

Reconsider what you spend on.

Figure out ways to save money.

Don't worry about the bills.

Do things that will increase your income.

Make the best out of money you do have.

Go bankrupt.

Try to cut down on spending so you can pay the bills.

Discuss the situation with other members of the household.

Get help to pay bills from family, friends, creditors, or other resources. 


\section{Joseph P. McFall}

-updated: 12/14/2007-

\section{CONTACT INFORMATION}

OFFICE

$\begin{array}{ll}\text { Address: } & 1222 \text { life Sciences Building } \\ & \text { PO Box } 6040 \\ & \text { West Virginia University } \\ & \text { Morgantown, WV 26506-6040 } \\ \text { E-mail: } & \text { Joseph.mcfall@mail.wvu.edu }\end{array}$

\section{PROFESSIONAL EXPERIENCE}
8/2007 - 5/2008 Graduate Teaching Assistant, Department of Psychology West Virginia University, Morgantown, WV
5/2007 - 8/2007 Graduate Research Assistant, Department of Psychology West Virginia University, Morgantown, WV
1/2007 - 5/2007 Graduate Teaching Assistant, Department of Psychology West Virginia University, Morgantown, WV
5/2006 - 12/2006 Graduate Research Assistant, Department of Psychology West Virginia University, Morgantown, WV
8/2005 - 5/2006 Graduate Teaching Assistant, Department of Psychology West Virginia University, Morgantown, WV

\section{EDUCATION}

2005 - Present

Life-Span Developmental Psychology Doctoral Program West Virginia University, Morgantown, WV

$2001-2005$

B.A., Summa Cum Laude, Sociology/Anthropology, Psychology, May 2005 State University of New York at Fredonia, Fredonia, NY

\section{HONORS}

\section{AWARDS}




\section{PROFESSIONAL AFFILIATIONS}

2005 - Present

2005 - Present

2005 - Present
American Psychological Association (APA)

Association for Psychological Science (APS)

Gerontological Society of America (GSA)

\section{STUDENT AFFILIATIONS}

2005 - Present

2005 - Present

2005 - Present
Association for Gerontology in Higher Education (AGHE)

American Psychological Association of graduate Students (APAGS)

Association for Psychological Science Student Caucus (APSSC)

\section{TEACHING EXPERIENCE}

Spring 2008

Fall 2007

Spring 2007

Spring 2006

Fall 2005
Introduction to Social Psychology, 2 sections of 60 students Introduction to Social Psychology, 2 sections of 60 students Introduction to Social Psychology, 2 sections of 60 students Introduction to Psychology, 1 section of 120 students Introduction to Psychology, 1 section of 120 students

\section{PROFESSIONAL ACTIVITIES}

November $2007 \quad$ Reviewer: APSSC Student Grant Competition

April 2006

Reviewer: APSSC Student Grant Competition

February 2006

Reviewer: APSSC Student Research Competition

\section{RESEARCH INTERESTS}

- Everyday problem solving

- Judgment and decision making

- Successful aging

- Risk prevention/intervention

\section{PUBLICATIONS}

Spielmans, G. I. \& McFall, J. P. 2006. A comparative meta-analysis of clinical global impressions change in antidepressant trials. Journal of Nervous and Mental Disease, 194, 845-852.

Spielmans, G. I., Passeck, L., McFall, J. P. (2007). What are the active ingredients in cognitive and behavioral psychotherapy for anxious and depressed children? A Meta-Analytic Review. Clinical Psychology Review, 27, 642-654.

\section{PRESENTATIONS}


McFall, J. P. \& Spielmans, G. I. (2005). Comparative meta-analysis of clinical global impressions scale change in antidepressant trials. Poster presented at the Eberly College of Arts and Sciences poster Session, October 2005, Morgantown, WV.

McFall, J. P. \& Strough, J. (2006). Collaborators' judgment and decision-making errors on individual and interpersonal problems. Poster presented at the $18^{\text {th }}$ Annual Conference of the Association for Psychological Science, May, 2006, New York, NY.

McFall, J. P. \& Strough, J., \& Mehta, C. M. (2007).Sunk cost decision making: Who has the advantage and why? Poster presented at $60^{\text {th }}$ Annual Scientific Meeting of the Gerontological Society of America, November, 2007, San Francisco, CA.

Spielmans, G. I., Passeck, L., \& McFall, J. P. (2006). What are the Active Ingredients in Cognitive and Behavioral Psychotherapy for Anxious and Depressed Children? A Meta-Analytic Review. Poster presented at 2006 American Psychological Association Convention, August, 2006, New Orleans, LA.

Strough, J., McFall, J. P., \& Flinn, J. A. (2006). Friends' goals for collaborative problem solving in early and later adulthood. Paper presented at 59th Annual Scientific Meeting of the Gerontological Society of America, November, 2006, Dallas, TX.

Strough, J., McFall, J. P., \& Schuller, K. L. (2007). Understanding everyday problem-solving performance in nominal and interacting pairs. Paper presented at $60^{\text {th }}$ Annual Scientific Meeting of the Gerontological Society of America, November, 2007, San Francisco, CA.

Strough, J., Schuller, K. L., Flinn, J. A., Mehta, C. M., \& McFall, J. P. (2006). Collaborating to make decisions: Are two heads better than one? Paper presented at 59th Annual Scientific Meeting of the Gerontological Society of America, November, 2006, Dallas, TX. 